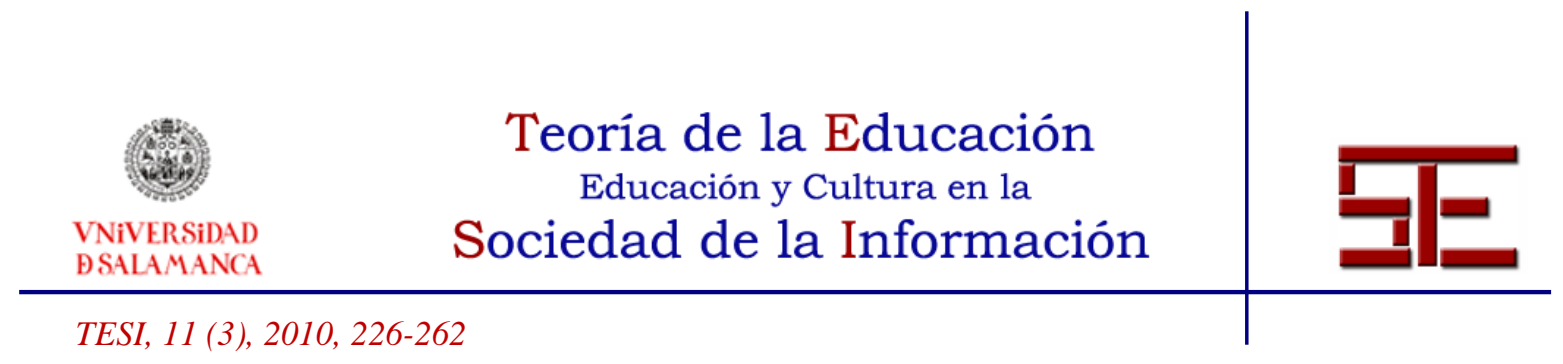

MOVIMIENTO EDUCATIVO DE LOS JUEGOS DE ROL. MAS ALLA DEL
ENTRETENIMIENTO

Resumen: El juego de rol educativo siempre ha demostrado ser una herramienta eficaz para los consultores tratando de desarrollar las habilidades que los empleados están utilizando para realizar ciertas funciones de trabajo. Sin embargo, mientras que el juego de rol a menudo se presenta como un medio de entretenimiento para el aprendizaje, tal insistencia en hacer juegos de aprendizaje más entretenidos, parece tener un efecto inhibidor en el diseño de juegos y el pensamiento más allá de la adquisición de habilidades simples. Al hacer hincapié en el juego de rol, proceso basado en una negociación conflictiva entre las categorías distintivas de los conocimientos, se presenta la solicitud de exploración de los conocimientos, tanto que se establece la facilitación de procesos reflexivos como la clave para trascender el conocimiento del contexto del juego a la de los participantes. Mientras, se apunta hacia los problemas de compatibilidad entre las concepciones actuales de los juegos de aprendizaje y la facilitación de los procesos de reflexión, el documento subraya la necesidad de pensar en el juego de rol educativo como parte de un diseño didáctico, en lugar de algo beneficioso en sí mismo.

Palabras clave: juego de rol educativos; desarrollo organizacional; aprendizaje; diseño didáctico; la facilitación.

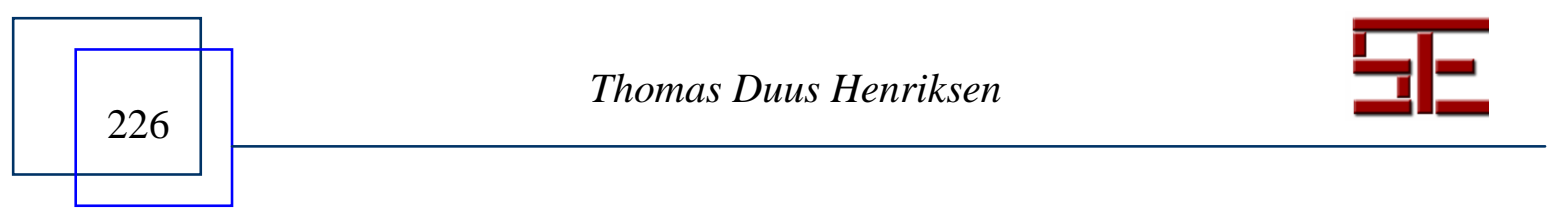




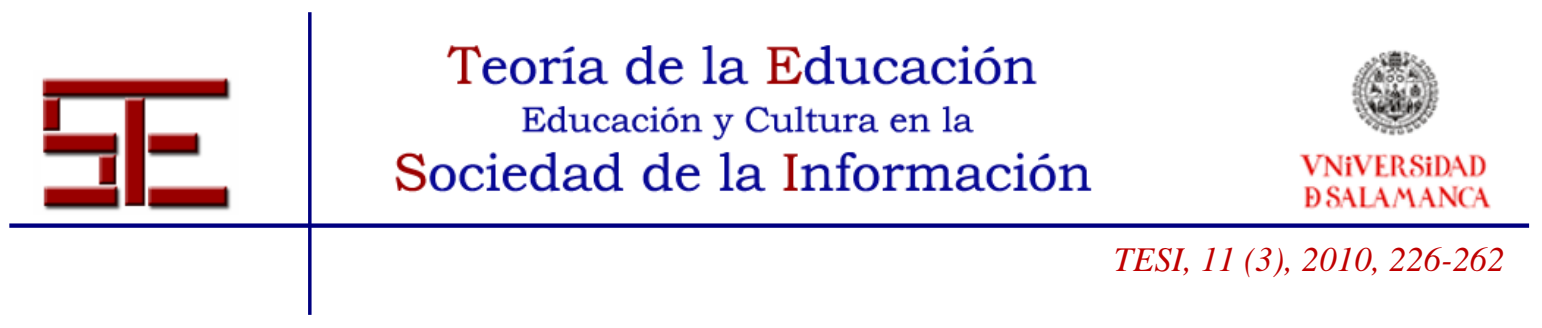

\section{MOVING EDUCATIONAL ROLE-PLAY BEYOND ENTERTAINMENT}

Abstract: Educational role-play has long proved an effective tool for consultants trying to develop the skills that employees are using for performing certain job functions. However, while educational role-play often is presented as an entertaining means for learning, such insistence on making learning games more gamish seems to have an inhibiting effect on designing and thinking games beyond mere skill acquisition. By emphasising the role-play based process as a conflictual negotiation between distinctive categories of knowledge, this paper presents the explorative application of knowledge, while framing the facilitation of reflective processes as the key for transcending knowledge from the game's context to that of the participants. While pointing towards the compatibility issues between current conceptions of learning games and the facilitation of reflective processes, the paper emphasises the need for thinking the learning game as a part of a didactic design, rather than something beneficial in itself.

Key words: educational role-play; organisational development; learning; didactic design; facilitation.

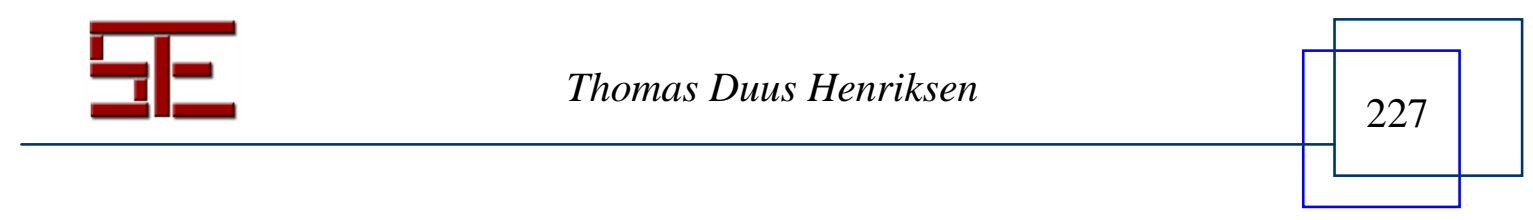




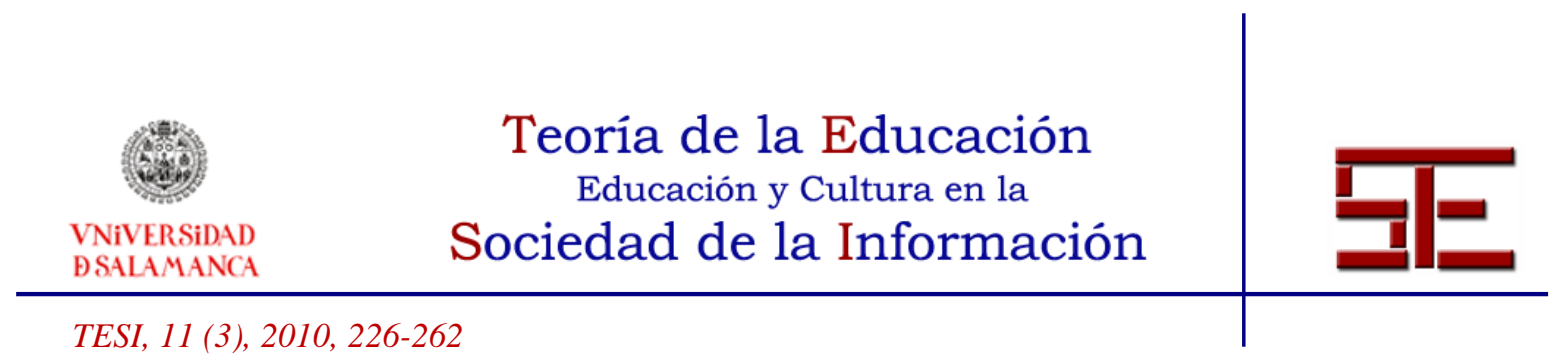

MOVING EDUCATIONAL ROLE-PLAY BEYOND ENTERTAINMENT

Fecha de recepción: 07/07/2010; fecha de aceptación: 01/09/2010; fecha de publicación: 30/11/2010

Thomas Duus Henriksen

tdh@dpu.dk

University of Aarhus

\section{1. - INTRODUCTION}

Games in various forms are currently enjoying a lot of interest across various educational settings, and it is becoming increasingly popular to proclaim games as the future for learning. One of the main reasons why games are being invited into learning environments is its ability to facilitate intrinsic motivation and make learning a pleasurable experience.

But even though games are being used for innovating learning environments, this innovative thinking does not seem to have affected the way of thinking games in general. The use of games in the educational setting generally seems aimed towards entertaining its participants (Papert, 1998), and as long as game providers and demanders meet each other on these terms, the educational use of gaming is likely stay stuck in the discourses of edutainment, an understanding of learning and games that is widely criticised (see Egenfeldt-Nielsen [2005] for a review). A similar tendency can be seen within the use of role-play for educational purposes, where such games are often portrayed as colourful contributions and energisers to the learning process.

One key consequence of this practice is that game based learning is being framed as an entertaining tool for training purposes, which I would claim to have an inhibiting effect on making them fulfil their main purpose, namely to provide the learning setting with sophisticated feedback on participant hypothesises and actions. Games may be able to contribute with as a provider of participational incentives, but a much more interesting contribution seems to spring from thinking games framed as feedback providers. This paper presents both arguments on why such reframing is interesting, as well as displaying a model on how such might be done.

By insisting that games should be brought forward for its ability to entertain, the fruitful exploration of alternative applications is inhibited, if not totally prevented. To my

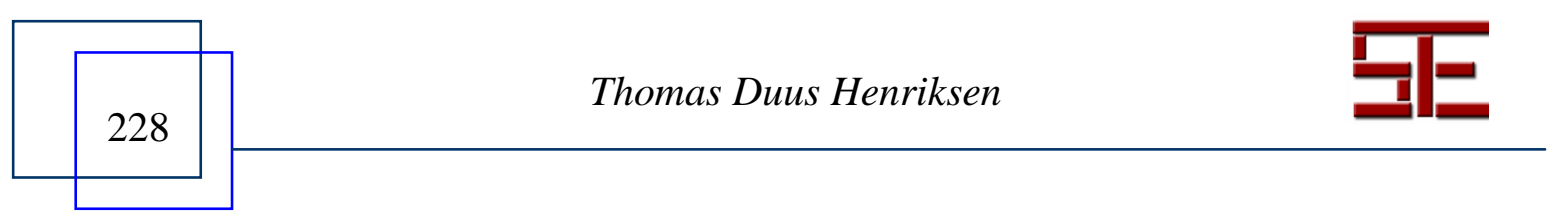




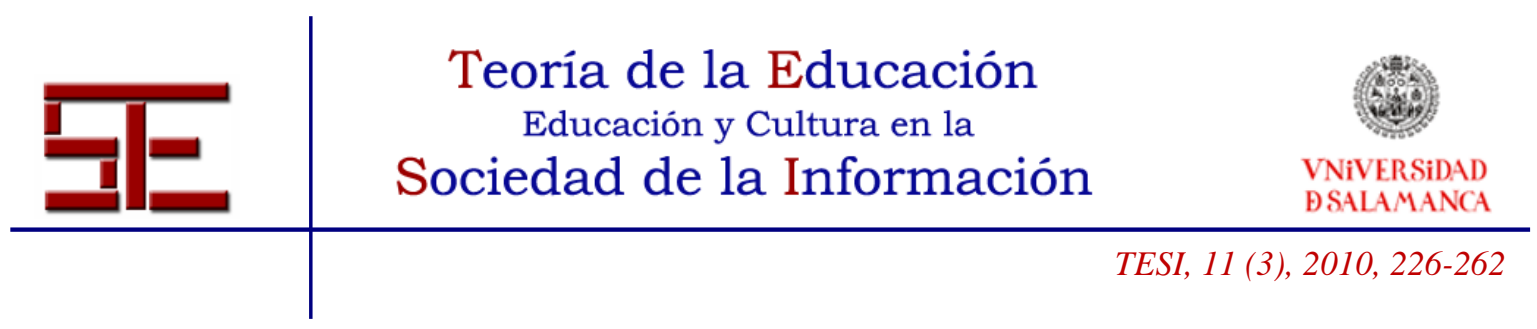

opinion, entertainment should only be viewed as a possible mean in learning games, rather than a definite goal. Similarly, emphasis should be placed upon the learned benefit, framing this benefit as the goal for the game based learning process.

If we are willing to innovate games on the one characteristic that is actually selling educational games today, we might be able to build better learning games. In order to innovate on this characteristic, we must allow ourselves to question the general assumption that the combination of games and learning should be entertaining. Better games learning are seen as not just funnier games, but games which actually provide its participants with relevant, usable and measurable learning benefits. The core of this approach to innovate learning games is fuelled by asking whether making games entertaining is the only participational incentive we have. The key question is therefore what the consequences are to the learning process and educational objectives if the participatory incentives of educational role-play is thought beyond entertainment? This problem is explored through the presented framework, using change learning as focus and the educational role-play 'Assessment Game' (AGame) as the main case.

\section{2. - FROM FUN AND GAMES}

Several writers have addressed the notion of making games fun, presenting different theoretical frameworks for producing participational incentives, usable for producing non-entertaining incentives. An influential fun-deconstructing framework is presented by Malon \& Lepper (1987), presenting a number of cognitive and social mechanisms that are often employed in game-based activities. Three other mechanisms or determinants that may be produced within the game setting and employed as incentives are tendencies towards seeking mastery or pleasure (Csikszentmihalyi, 1975) or Piaget's concept of equilibrium (see von Glasersfeld, 1995). The core concept of the latter three is to place the participant in less desirable situations, instead of placing him in an immediately pleasant situation, thereby producing a drive towards the more desirable situation. A model for such participational incentives is presented late in the paper.

The concept of using such processes in learning environments is not a new one, and has previously been presented by Lewin (1947) and Schein (Schein, 1962) (see Høyrup, 1975 for a review), long before role-play was framed as a mean for entertainment (see Konzack, 2003). The new thing is how we can meet current and future educational demands, how they affect our understanding of learning games and if we can design learning games that helps us in doing so.

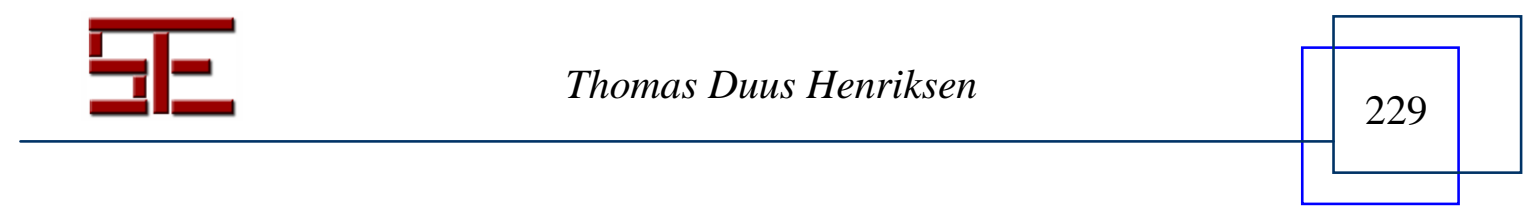




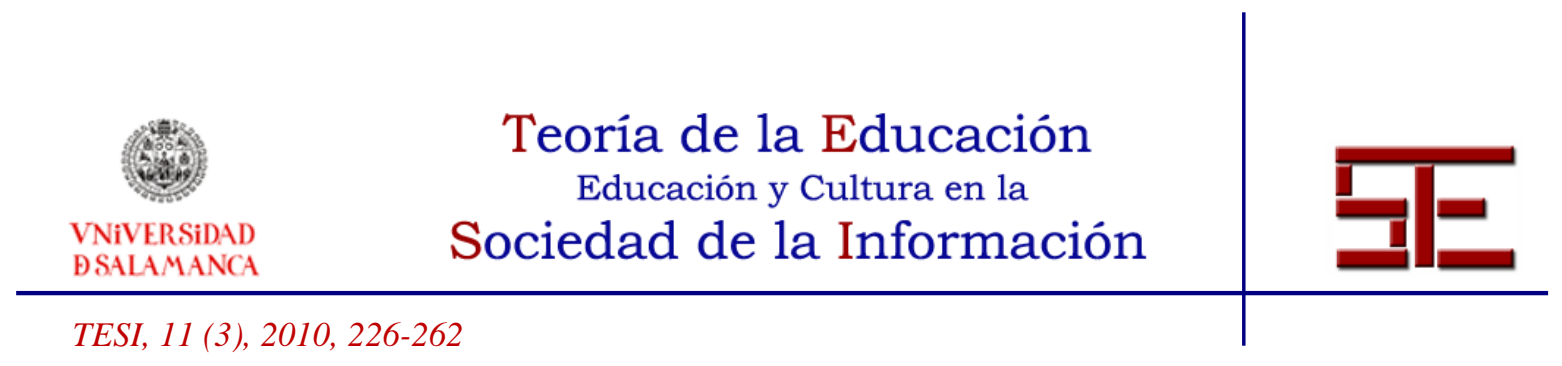

A current tendency within educational demands is an emphasis on processual knowledge, such as reflection and change. These objectives are interesting as they both are concerned on what is learned and how it is done. Another tendency is the demand for learning environments that help participants in associating theoretical knowledge and practical application as well as taking the participant's existing knowledge and competencies into consideration.

Emphasis in this paper is placed upon producing personal or organisational change. Change and change management often implies an essentialistic approach to learning, allowing someone outside the learning organism to decide what is essential to learn, rather than letting the participant decide. A role-play based approach is used to present a frame for how change management can be facilitated, as well as how personal knowledge can interact with the process, thereby producing a more existentialistic alternative to the essentialistic defined learning objectives.

The aim is to provide an example on how learning games, based on role play, can be utilised in order to meet the objectives concerning benefit and requirements stated above. To do so, a theory of the role-play-based process must be formulated in order to grasp the basis for the learning process. Furthermore, a theoretical understanding on learning must be applied, taking both role-play as a process into account, and on the same time grasping the use of alternative incentives. These approaches are briefly sketched below.

\section{3. - UNDERSTANDING THE ROLE-PLAY BASED PROCESS}

Role-play is investigated as media for the game based learning process due to its ability to combine the participant's personal perspectives with those of an external character into a role (Henriksen, 2004), and its ability to place this combination in a simulated practice (Henriksen, 2000). This ability to combine perspectives allows us to build sophisticated and individualised participational trajectories across a game practice. This makes the role-play an effective tool for creating specific experiences that can be utilised for learning purposes, as well as bridging new and existing knowledge, thereby creating the basis for constructivist orientated learning processes.

Educational role-play consists of three elements; first on role-play, second on gamebased learning, and third on learning in general. Role-play is considered ".. a medium where a person, through immersion onto a role and the world of this role, is given the

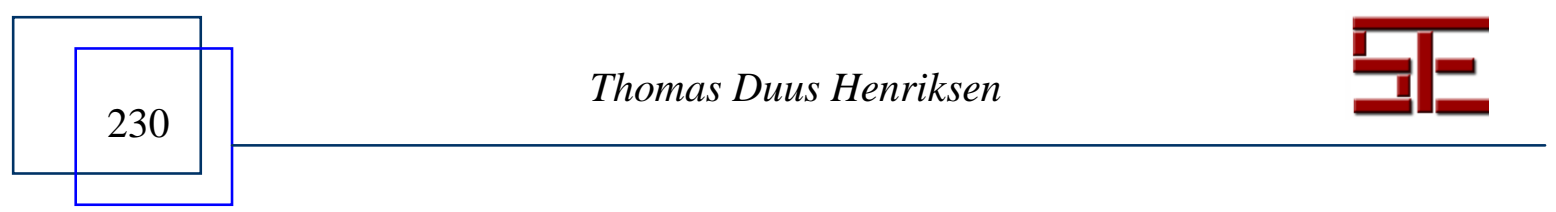




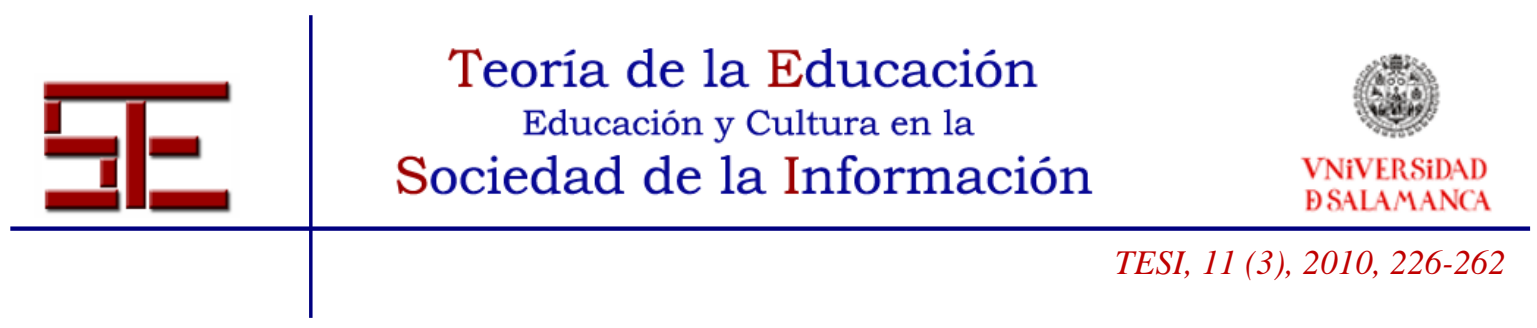

opportunity to participate in, and interact with the contents of this world, and its participants" (Henriksen, 2003:110, 2004:54). This provides the learning setting with an element of interaction and feedback, as well as an explorative approach to the content of the game.

When it comes to games and learning, an important distinction lies in the difference between learning games, games used for learning purposes, and game-based learning processes. Learning games are developed and applied with the explicit purpose of educating its participants, and this feature makes them distinct from commercial games that are used for educational purposes. Whereas the first is developed in order to facilitate and support learning, the second is developed in order to entertain and sell copies, while some can be used for educational purposes (e.g. Europa Universalis II as described with Egenfeldt-Nielsen, 2005). The third type, game-based learning processes are elements, which are recognizable and sometimes usable in games used for learning such processes are the building blocks of learning games. These game-based elements are then integrated into a didactical design. As learning games have an explicit purpose, that is to facilitate learning, the game must facilitate learning processes, through with learning can take place. This could, for example be a feedback mechanism, an opportunity to explore an enriched, academic content, or the facilitation of reflection upon the game-provided experience.

The third element of an understanding the process is the learning perspective. A common distinction is often made between implicit and explicit learning processes. Edutainment usually rely on implicit processes (as seen with Prensky, 2001), whereas education in general is seen as a deliberate, explicit process, turned towards an objective (see e.g. Lave, 1999). This provides the learning game with a purpose, which affects the participational incentives; the learning games does not have to lure its participants into the game by competing with other entertaining activities, the overall incentive is provided - all the game has to do is to immerse the participant into the relevance of the learning objective.

Educational role-play can therefore be seen as a media, which is explicit on its purpose, allowing a participant to immerse into and interact with a setting, which is enriched by an objective relevant content, as well as mechanisms that facilitates learning, taking existing personal knowledge of the participant into account in the learning situation.

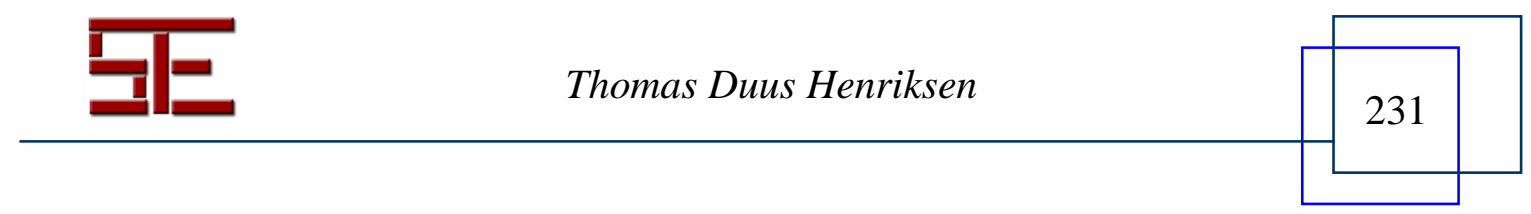




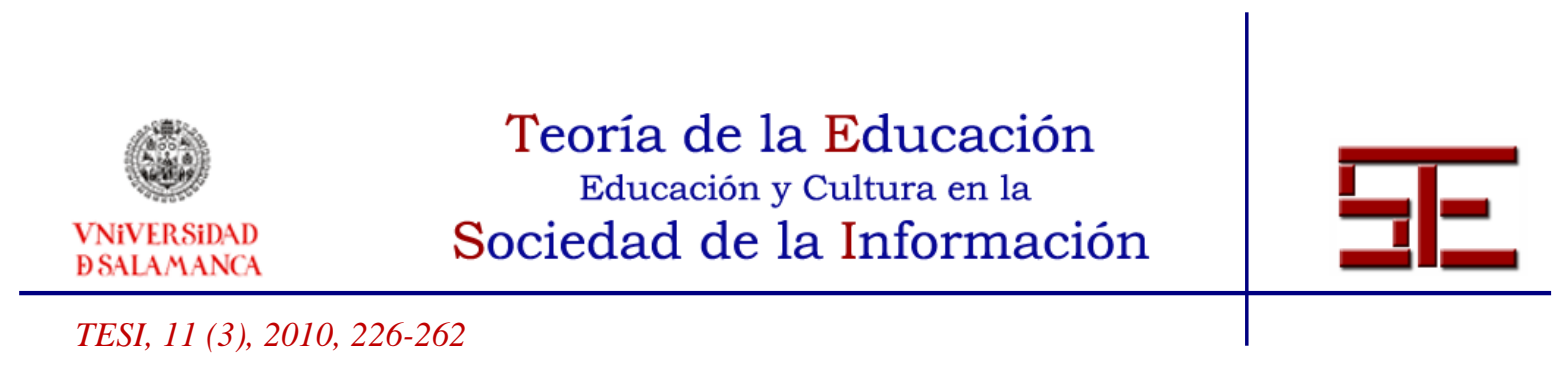

Such definition calls for three areas of attention - first towards the participational incentives concerned with engaging the participant, second the feedback mechanisms concerned with turning the game into an educational setting, and third the content providing elements used for communicating relevant perspectives to the participants. These issues are investigated throughout the paper.

Another key issue explored is the element of immersion, the sensation of being surrounded by another reality (Murray, 1997:98), making the game setting, problems and goals staged as actual and relevant to the participant (Henriksen, 2002). Such focus on immersion allows for the exploration of alternative participational incentives, e.g. how frustration, narrative desire or cognitive dissonance affects participation. The aim for such exploration is to explore how such incentives affect the game process, thereby providing the game designer with more tools for building effective learning games.

\section{4. - COMPETING PERSPECTIVES: PERSON VS. CHARACTER}

In order to understand the learning aspect of such approach games, two issues of learning theory are relevant to include; first the theoretical approach that helps us understanding the benefits of the role-play based process, second, the learning theory must also be able to grasp the effect of the alternative participational incentives.

The main emphasis is placed on how we can understand the process and consequences of utilising the alternative incentives. Two major contributions to such theoretical construct are the educational perspectives of Piaget's radical constructivism (von Glasersfeld, 1995) and those of Schein's (1962) unfreeze-move-refreeze framework. A post-structuralism framework is used to draw attention towards the interplay of the participant and the context provided by the game. Emphasis is placed upon how the participant's understanding is affected, partly on the experience created by the learning game as a whole, partly on the (conflicting) perspectives of the game.

\section{5. - CONSEQUENCES FOR THE LEARNING GAME DESIGNER}

A main consequences of the framework presented in this paper, is that it requires the game-designer to utilise a wider variety of participational incentives, instead of merely sticking to entertainment. Such incentives could include, but are not limited to fruitful frustration, irritation, narrative desire, social roles and frames, etc. Malone \& Lepper (1987) presents a variety of such incentives, but are rather brief on incentives that are

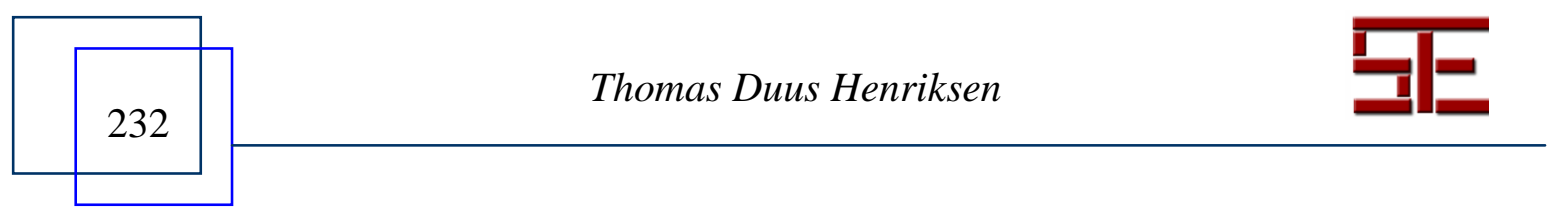




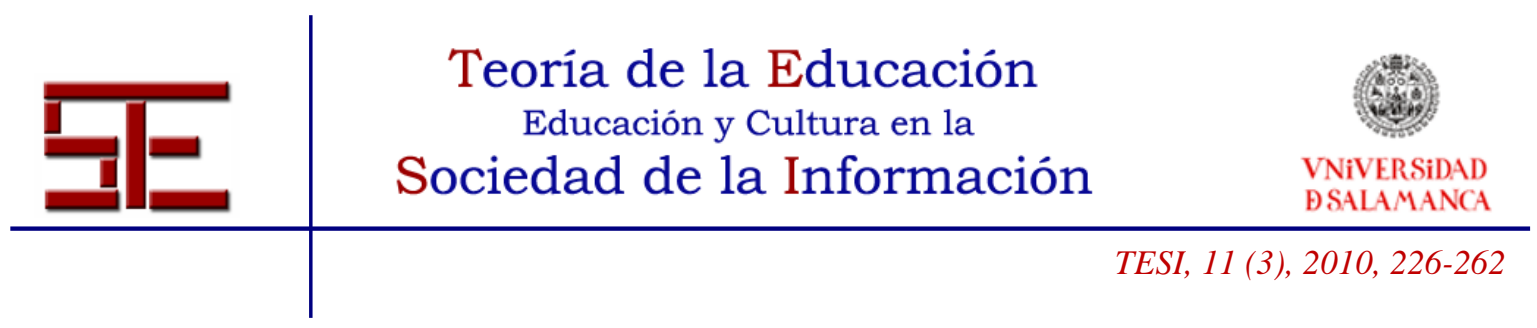

not immediately pleasant to the participant, which calls for a further exploration of such alternatives. My reason for using the term entertainment rather than fun is that entertainment is seen as something immediately pleasant, whereas fun can consist of a number of staging events, which in themselves can be frustrating. When the frustrating element is resolved, pleasurable fun occurs as a relief (e.g. the situation when the participant places a number in a sudoku game). A popular framing of such fun is Papert's (1998) concept of hard fun, utilising fruitful frustration as a driving incentive.

\section{6. - THEORETICAL APPROACHES}

In attempt to understand the entertainment-alternative incentives, attention must be turned towards how these incentives appear and affect the role-play-based process, and in particular how they affect the participant's experience of the game. One approach to understanding such effect is to employ a structuralist approach to understanding interactions taking place between the role-play as a structure and its participant. Such approach presents an anti-humanistic approach to science, rejecting that meaning is embedded in tings themselves, and instead turns to understand how various structures manifest and affect a phenomenon (Gregersen, 2003). Such approach is relevant to investigate both role-play and educational settings, as the investigation seeks to explore how underlying story or knowledge elements affect the learning situation, and not just how the game based learning process takes place and appears, as would be the case of a phenomenological approach.

The structuralist approach implies a determination of the subject's action. Such approach is relevant for understanding essentialistic learning environments that seek to determine the learned outcome, as well as with games, which seeks to produce a certain fantasy or perspective among its participants. Role-play based learning situations distinguish themselves from such pure essentialistic settings by allowing the participant to co-create his problems, applied strategies, perspectives and experience, requiring an approach that does not understand the game structure as completely determinant to the game outcome. A very common experience from using games, and especially cocreative games like role-play, is that the outcome cannot be totally determined from the design. Instead, the participant becomes a factor, but as a factor within the determining frame. Such co-creative span between the participant's actions and the determining frame is addressed as agency within the post-structuralist approach to science, presenting a frame for understanding this relationship.

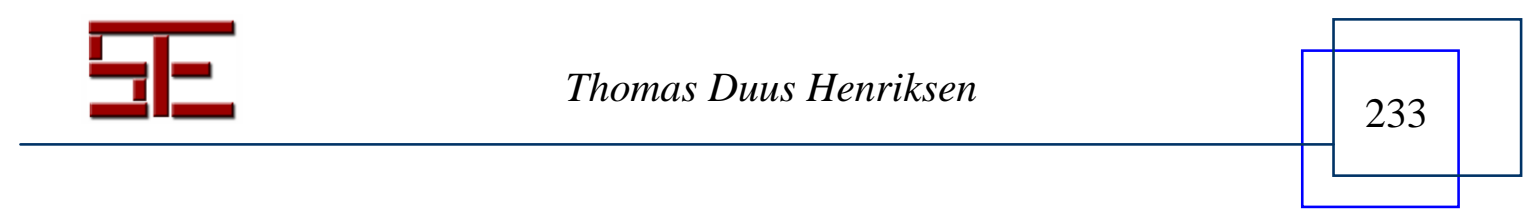




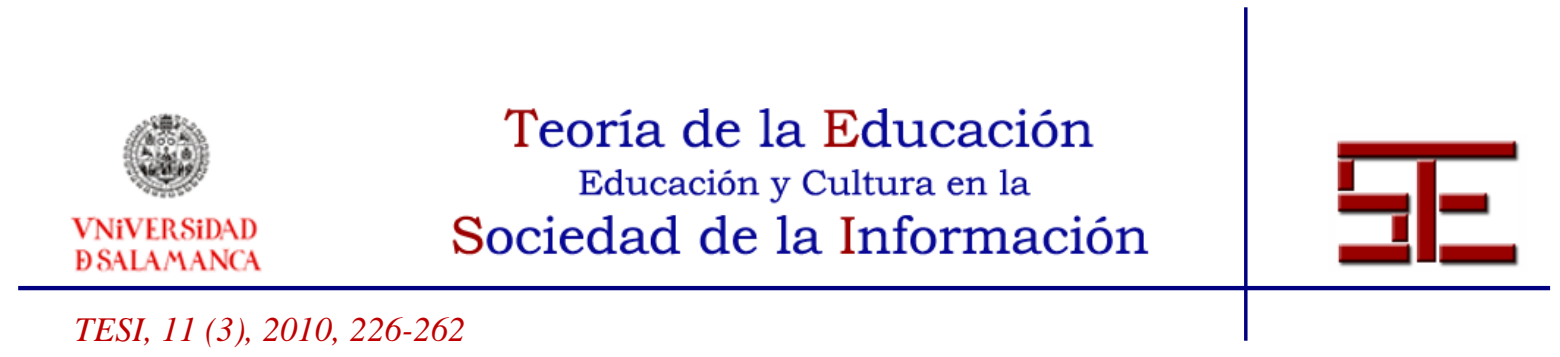

\section{7. - SCHEIN'S FRAMEWORK OF LEARNING}

In order to facilitate change, an approach is needed that provides the participant with sufficient incentive to abandon one perspective for another. Schein (1962) provides such framework though the unfreeze-move-refreeze-approach to learning. This approach seeks to provide its participant with an incentive for change, which can be utilised for facilitating assimilative processes by encouraging the participant to learn more within an existing frame of knowledge, and for facilitating accommodative learning processes, thereby encouraging the participant to replace or abandon certain perspectives.

The model consists of three elements; an unfreezing effort, aimed at motivating the participant, usually through a disconfirmation of perceived perspective- or approach sufficiency to a certain problem; a move feature, allowing the participant to evolve new and more effective perspectives; and a refreeze effort, used to integrate the learned benefit with the participant's self image, personality, existing knowledge structures, etc (Høyrup, 1975).

The main purpose for the unfreeze effort is to provide the participant with incentive for participating in the learning environment, thereby motivating the learning process. One way of doing so, is by rendering existing knowledge insufficient, a desire to acquire new and problem sufficient perspectives is according to Schein (Schein, 1962) established. Such tendency is similarly presented as a desire for pleasure or mastery (Csikszentmihalyi, 1975) or equilibrium (von Glasersfeld, 1995). In order to produce the unfreezing, the participant must reflect upon the sufficiency of existing knowledge and how this knowledge affects his adaptability. In concern to learning games, this process can both be produced through staging and task definition.

The purpose of the move phase or element is to provide the participant with a perspective rich learning environment that allows him to acquire the perspectives relevant to handling the events, which originally produced the incentive for learning. Of particular interest to this paper is how games can provide a setting for matching the success of various perspectives across different problems. In concern to learning games, this process is created through problem solving activities.

The finishing integration of acquired knowledge through the refreezing phase has proved to be the most difficult process of the three (Høyrup, 1975). Both personal and interpersonal measures can be utilised in order to ensure stability and duration of the

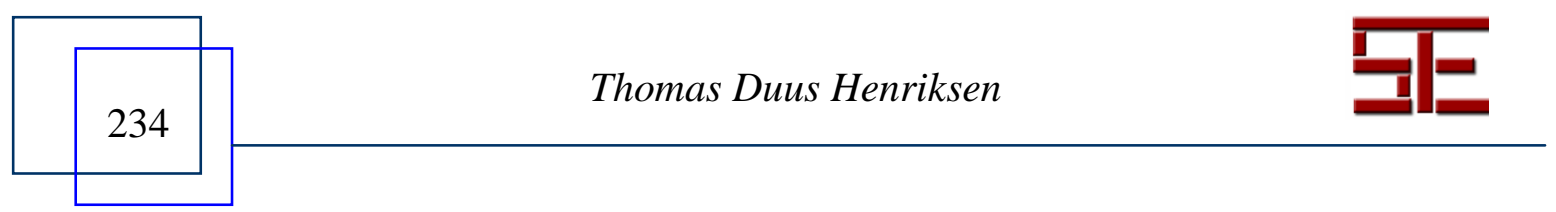




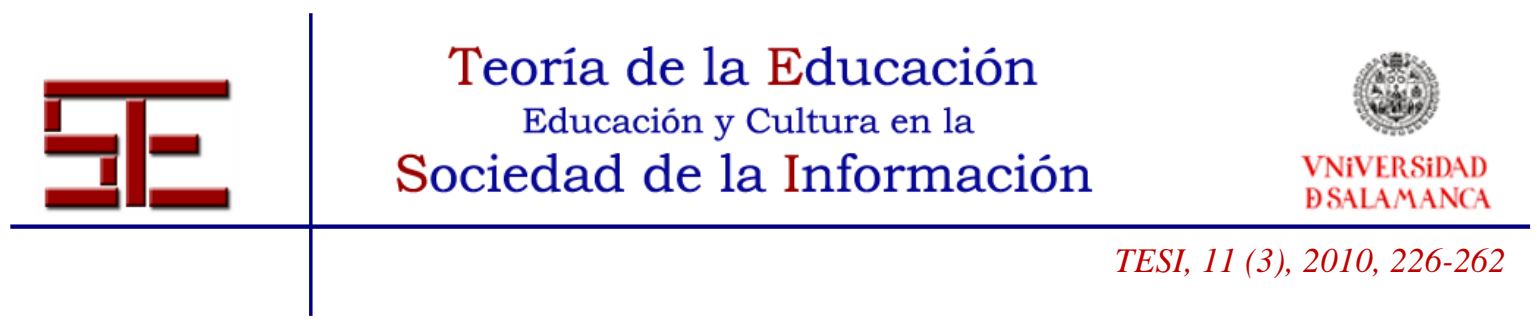

new perspectives (ibid), which can be produced though an experience of in-game mastery or through reflection. The refreezing process may be problematic in concern to existing knowledge, producing accommodative processes, or if not properly conducted a destabilising state of cognitive dissonance. Caution should therefore be taken in order ensure a proper completion of the process. A binding part for the three stages is the need for reflective processes, first in order to realise the insufficiency of current perspectives, second to measure the adaptability of various approaches during the move, third to integrate new and existing knowledge, and finally in order to transfer the refrozen perspectives to other contexts. The three stages are later on in this paper applied to roleplay in order to form an understanding of how role-play based learning can be used for facilitating change learning.

An issue in producing change, whether on a personal or organisational level, implies an orientation discussion between the educational philosophies of essentialism and existentialism. Whereas essentialism indicates a position stating that someone external to the learning organism can decide what perspectives are relevant to learn, existentialism takes to contrary position, stating that only the selection of perspectives to be learned only can be decided from within the learning organism. In this paper, a position near the essentialistic perspective is applied, as change facilitation consists of breaking existing practice within an area, as well as presenting and implementing perspectives that have not been accepted by the praxis. A main point in Schein's model is the initial unwillingness to learn - why would there be a need for an unfreeze manoeuvre if the participant was willing to learn the presented knowledge?

An essentialistic approach to learning is likely to produce resistance, which also has to be handled. Schein uses the unfreeze manoeuvre to eliminate eventual resistance ground in self-sufficiency, and to produce incentive for further participation and learning. This makes his framework a interesting tool for facilitating change. This application does not mean that learning games always has an essentialistic approach or content, it is rather a framing of educational role-play as a powerful tool when facing educational problems within the area of change or other essentialistic challenges.

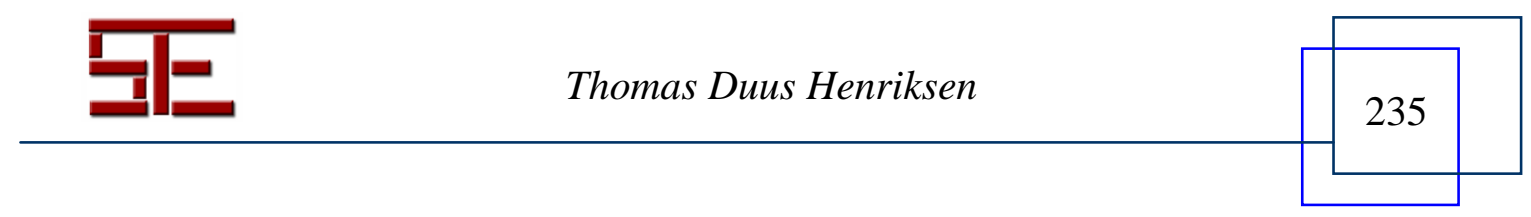




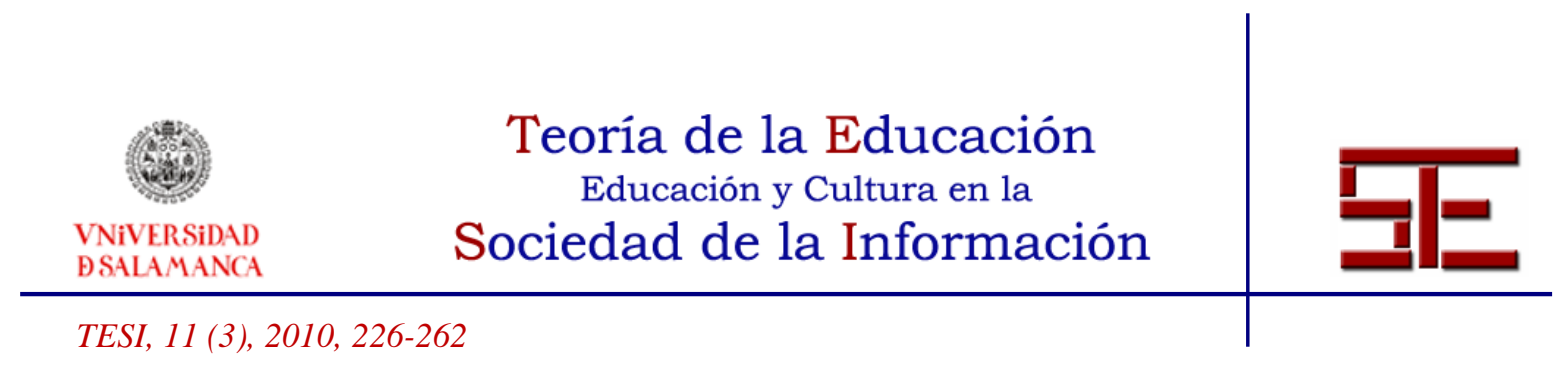

\section{7. - ROLE-PLAY: TWO MODEL FOR UNDERSTANDINGS STRUCTURE AND PROCESS}

Two models are presented in order to address that agency produced in role-play, which is utilised for the educational purpose. A structural model is displayed in order to frame the processes, whereas an interpretative model for analysing perspectives and interpretations is used for understanding the production of meaning in the game.

\subsection{The Structural Model}

Another model concerned with the question of agency played out between the participant and the frame produced by the game, is the structural recentering model (Henriksen, 2004, p. 110-111), here labelled as the structural model. By applying the core focus of social psychology to the process of fictional recentering in role-play, thereby identifying three levels of attention. These three levels; the contextual, relational and individual, can be used individually in order to create the desired situation for the agency in the educational role-play.

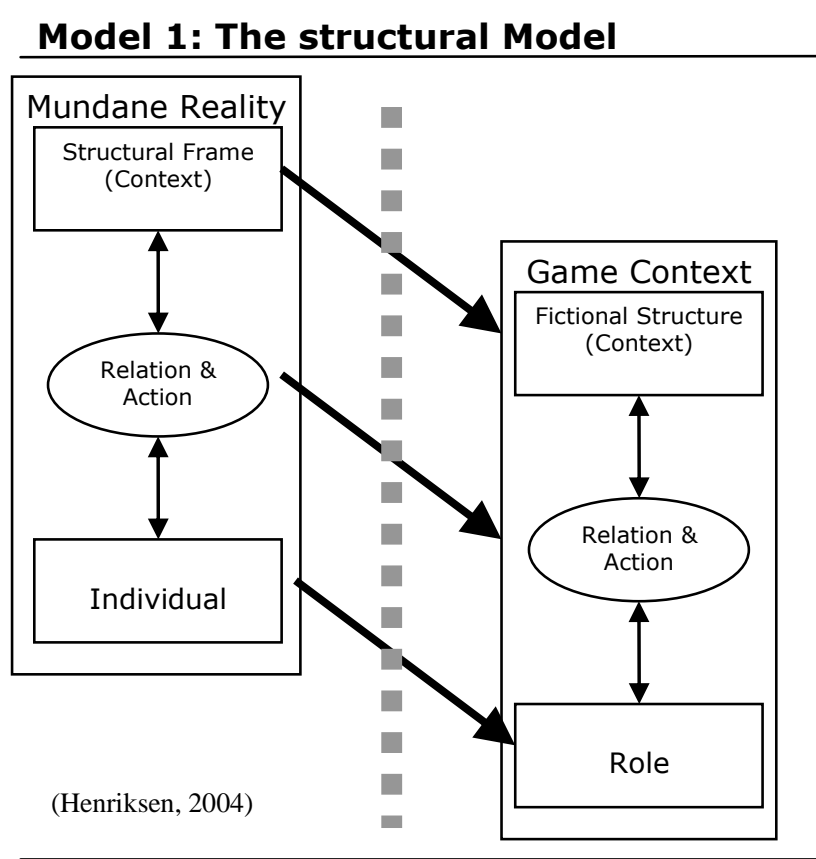

\subsection{The Interpretive Model}

The model interpretive model addresses the participant's perspective in the role creation process, seeking to form an understanding that can be utilised for building game-based learning processes (2005). The main point of the model is to point out the various perspectives, which together form the participant experience.

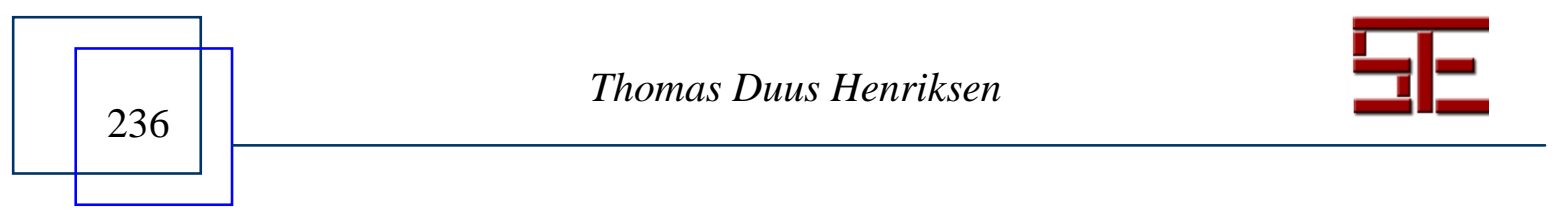




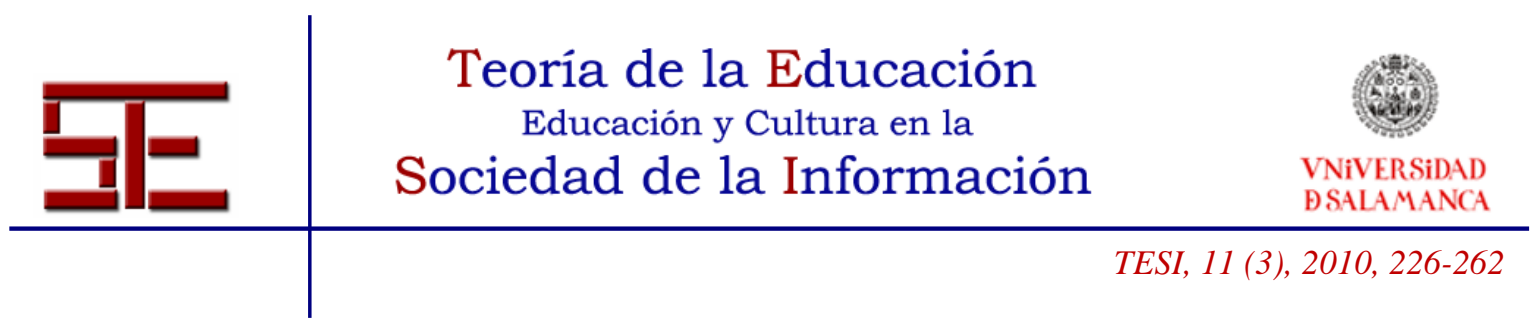

\section{Model 2: The Interpretative Model}

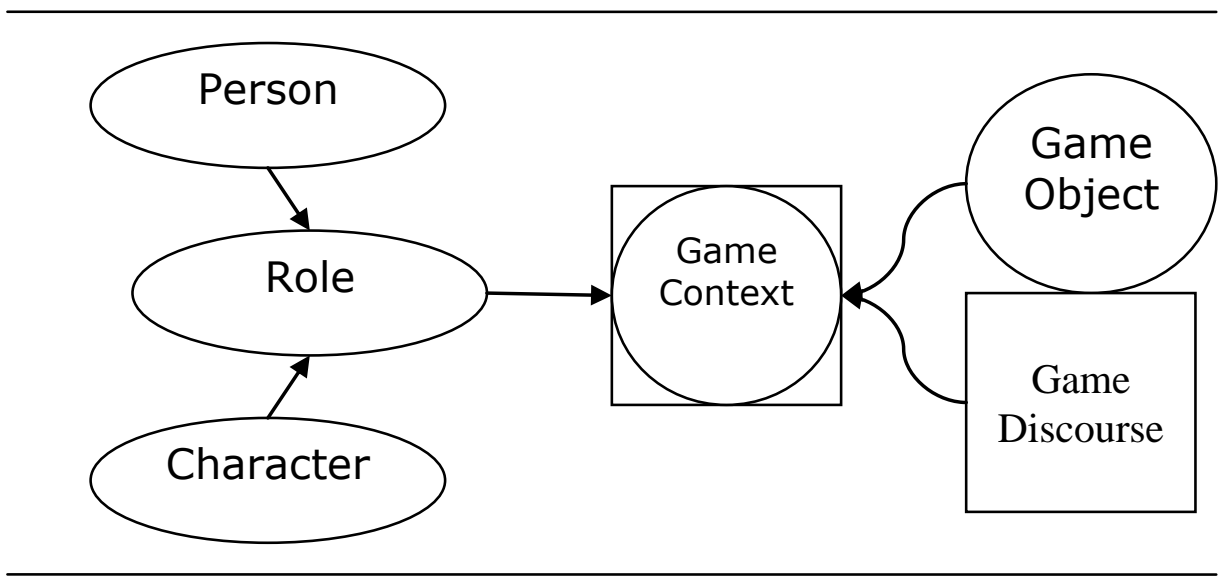

In the centre of the model, the game experience itself is represented. To the left are the elements, helping the participant in forming the individual perspective used during the game, to the right are the elements forming the structure of the game, together creating a sphere of agency.

The left side of the model consists of three elements or perspectives, which together form approaches to the game (presented on basis of Henriksen, 2004):

Person: Reflecting the mundane participant, including the participant's knowledge, values, beliefs, goals, habits, personal approaches, preferences emotions and the like.

Character: Represents the perspectives that the participants are to apply to the game. This could consist of playing a specific person (including what personal perspectives that might bring), or merely selected theoretical perspectives that are to be tested on various problems during the game.

Role: Represents our personal interpretation of the character, and consists of a mixture of perspectives from the participant's personal repertoire and selected elements of the character.

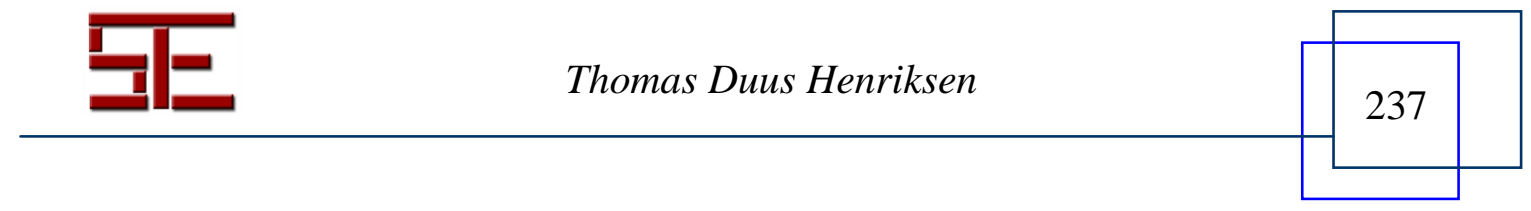




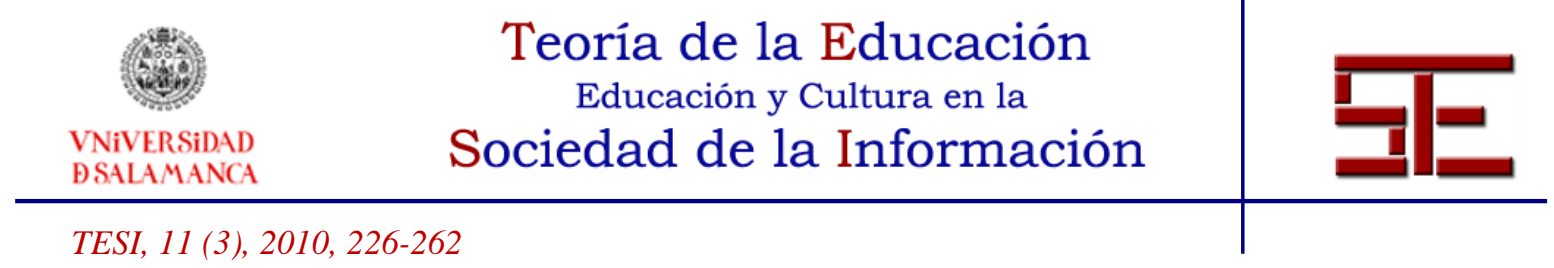

The elements on the right side represent the frame that the participation is played out in. It consists of a number of objects or phenomena, which are subject to interpretation, and a number of perspectives and discourses, from which the previous are interpreted (Henriksen, 2002). In this paper, less attention is paid to this side of the model, as the application below focuses on the different perspectives of the left side, across contexts of participation, rather than the experience produced by the mix of signs and symbols in the constructed frame (see Henriksen, 2004:112-113).

Together, the two models each address the agency in role-play. The structural recentering model identifies the three levels of attention, while the interpretative model addresses the content of these three levels; the left side describes the construction of the various perspectives, forming the basis of the individual approach to the agency, the right side (which is not addressed in detail) describes the structure within which the agency is taking place. Between them, in the middle of both models, is the interaction between the two, thereby forming the agency itself.

\section{8. - MAIN EXAMPLE: THE ASSESSMENT GAME}

The assessment game (AGame) was a part of the effort done to implement the consequences of the political reform "Flere i Arbejde" to the Danish unemployment sector. The purpose of the game was to change the assessment practice among employmency workers through the implementation of various tools for preparing and conducting the assessment of citizen who approach a job centre or a requests a social service due to unemployment. AGame was employed by the National Labour Market Authority and developed by the company RiA (www.reflection-in-action.dk). Running the game based implementation was mainly conducted during 2004 with a combined total of more than 3000 participants, from which I have personally experienced 30 games with an estimated total of 400 participants.

The AGame was preceded by a 3-hour lecture on the content and consequences of the reform, as well as a verbal demonstration of various tools, supporting the idea of the reform. After lunch, the participants played AGame in small groups, where they, confronted with simulated tasks, were given the opportunity to explore and experiment

\footnotetext{
7 'Flere i Arbejde' is a political Danish slogan, which can roughly be translated into 'More in Jobs'
}

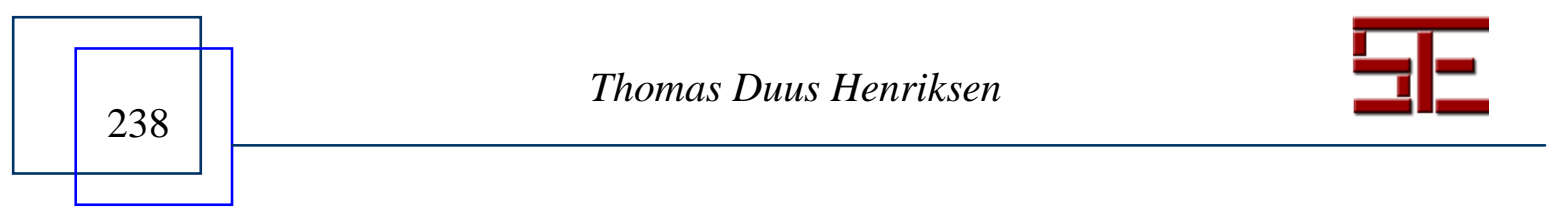




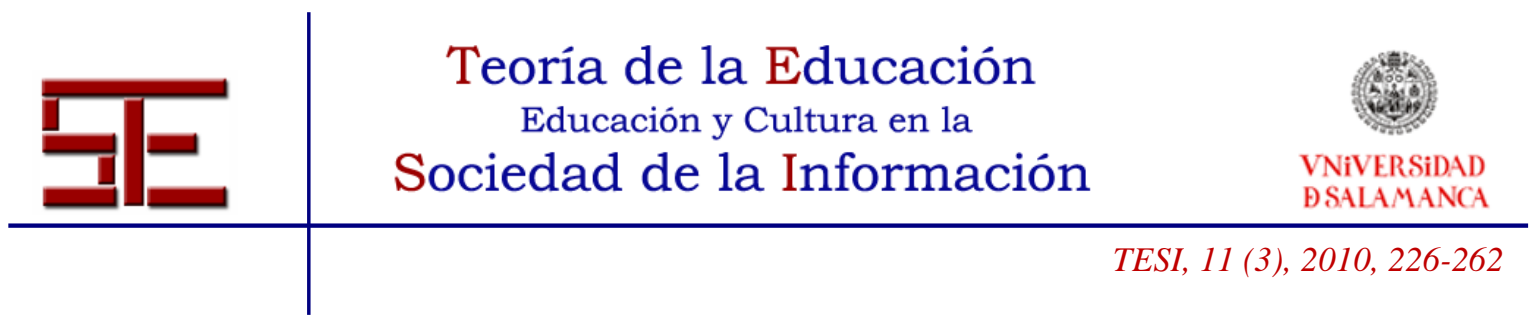

with the tools. The participants were clearly resistant to change at first, but in the confrontation with selected problems, the tools proved their use over current (personal) approaches. After playing the game, a reflective process was facilitated, allowing the participants to attribute some success of the tools to the specific context, but also helped building connecting bridges to their own daily praxis (mundane reality).

In overall terms, the game-based experience helped the participants moving from a resistance towards the change that the tools would bring, into a task where the tools proved essential, to a reflective combination of tools and personal approaches, and finally a change of mundane praxis.

The applied example is used as it utilises role-play in an educational setting, focussing on the implantation of producing change on both a personal and an organisational level. The intervention takes an essentialistic approach to change, as it attempts to implement certain perspectives and practices into a working practice.

\section{9. - CONSTRUCTING EDUCATIONAL ROLE PLAY FOR CHANGE LEARNING}

Whereas the structural model describes the fictional recentering of context, participation and participant, the interpretative model describes the construction of interpreting perspectives in role-play (Henriksen, 2004). Together, they address the relationship between participant and game structure, allowing the issue of agency in game based learning processes to be addressed. By using role-play as the core for the game based learning process, personal perspectives can be addressed through the learning process. If game based learning fails to take existing knowledge into account, the creative construction of personalised understandings are likely to fail in taking place, and, according to Galarneau's (1999) connectivist approach to game based learning, imply the risk of creating non-applicable islands of knowledge.

In order to implement the progression from Schein's model (first performing the unfreeze procedure, then moving the participant's perspective, then refreezing it at a new state), the right side of the interpretative model is replaced with three contexts; the mundane reality, the game context and a reflective sphere. This also done to bring attention to the participant's agency in and across the different contexts of the learning environment. Such a presentation of the model does not present the proceedings of the game, and therefore neither the communication of the character perspectives

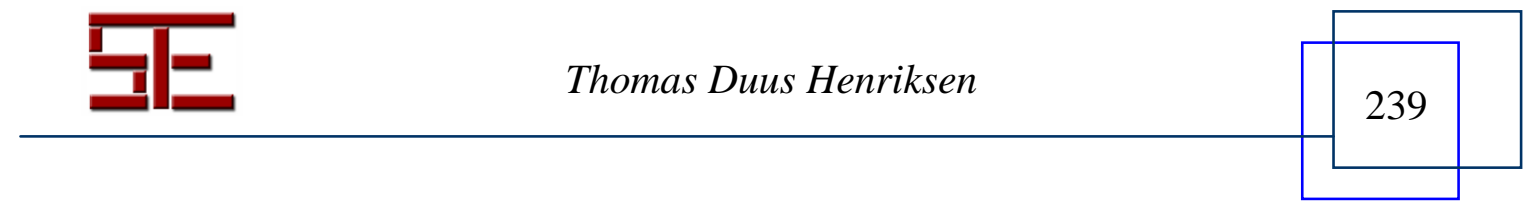




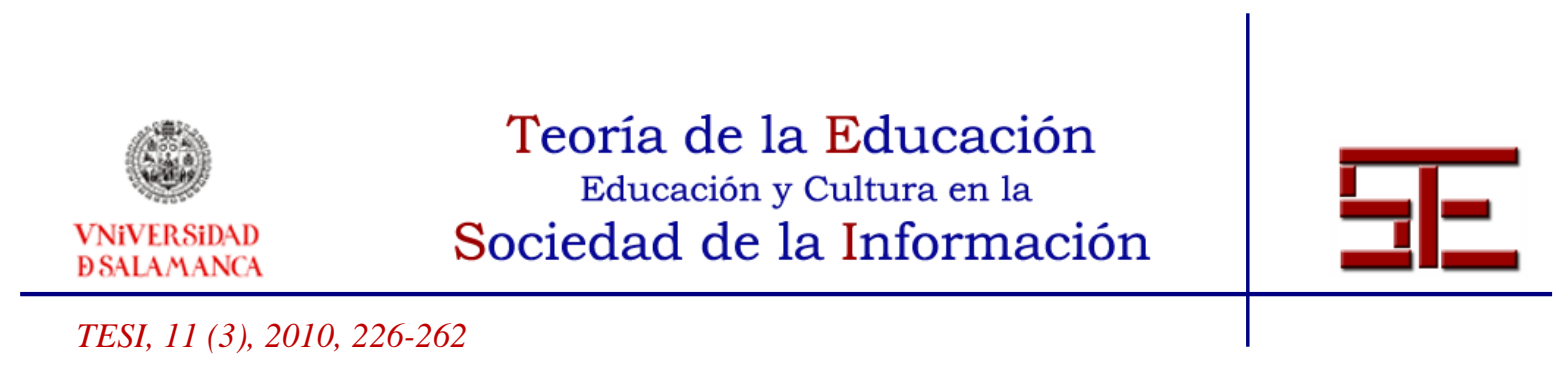

(knowledge, position, values, beliefs, goals, etc.) to the participant, although such communication is crucial for using the game based learning approach.

Model 3: The Perspective Model

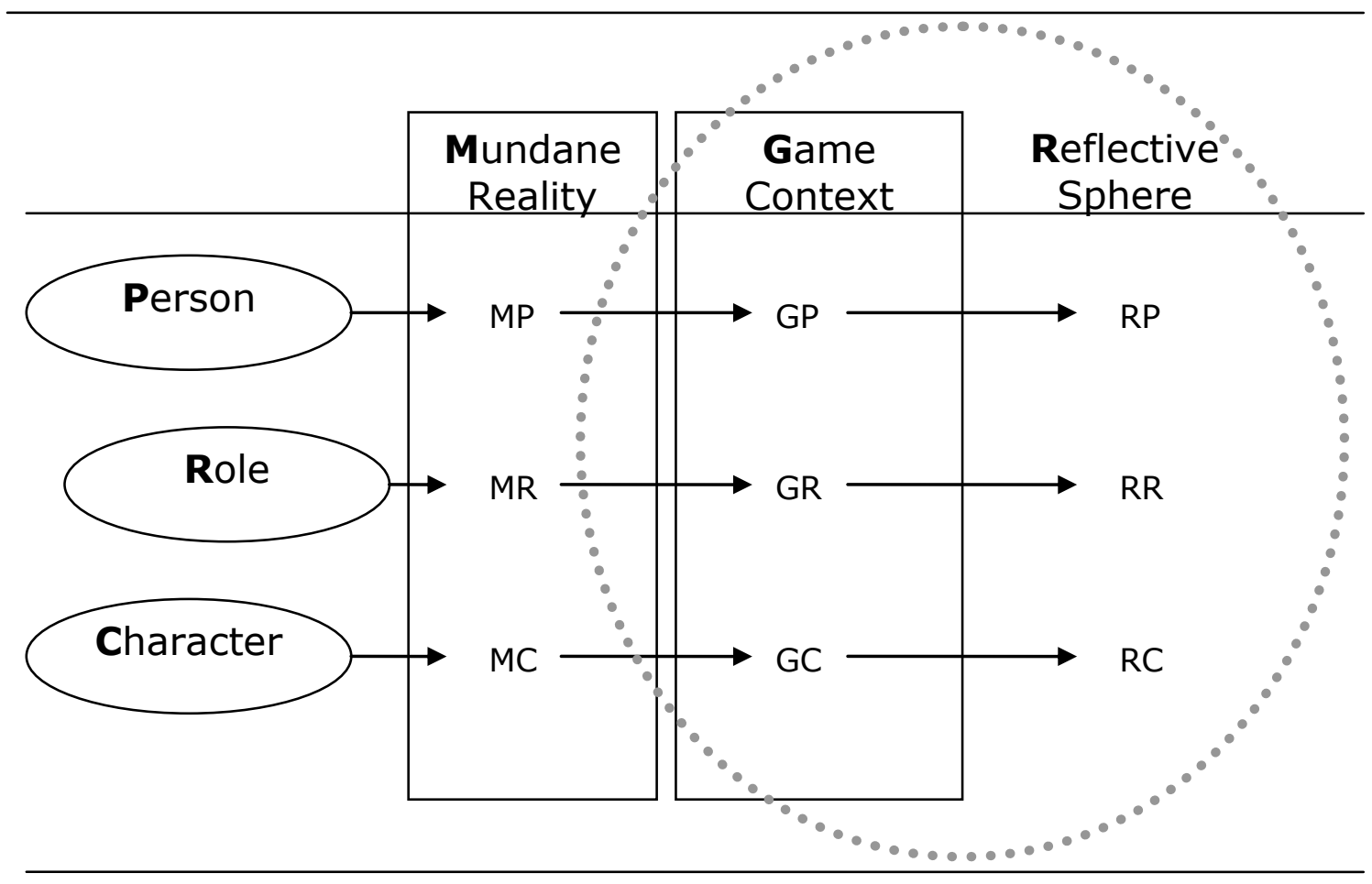

Particular interest is paid to the three levels of knowledge; personal, role and character, from which the participation takes place; the participant carries along his or her usual knowledge and understanding, commonly referred to as personal perspectives. The perspectives of the character are presented to the participant before the game, and are expected to, in various degrees, to affect the participation during. Finally, a combined perspective of the personal and character perspectives are used as basis for participation, although the other perspectives may influence participation. The three levels of knowledge, existing (person), new (character) and the combination (role) are investigated across the three contexts, referred to as mundane reality, game context and reflective sphere. These are understood as the following:

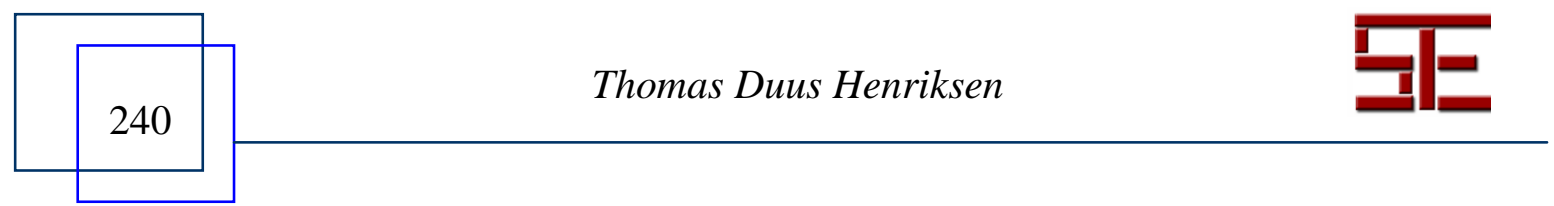




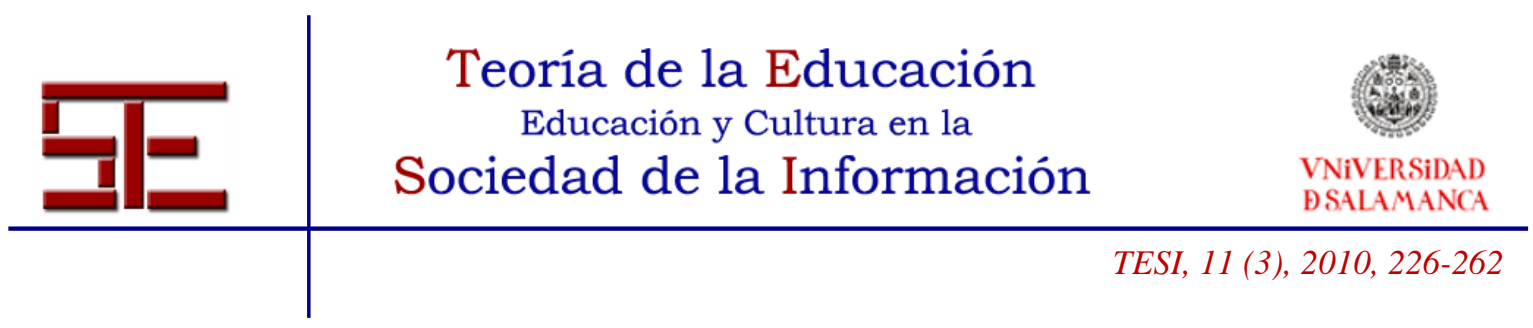

\subsection{The Mundane Reality}

The mundane reality refers to our everyday context as the practice where existing knowledge is being used, and where the new knowledge is supposed to be used. This mundane reality is typically characterised by having a greater complexity than the game context and by being the aim for the game-based learning process.

\subsection{The Game Context}

The game context refers to the game itself; a temporary sphere of participation, governed by rules, and based on the acceptance of a temporarily accepted, but otherwise (normally) rejected discourse. This context is in learning games seen as experimental spheres of application and exploration for personal and character perspectives towards a given practice.

Due to the qualitative element of role-play, the outcome of such a learning game is not seen in terms of a quantifiable outcome (in contrast to Salen \& Zimmerman's definition, 2004:80), but rather as the development, redevelopment, or, according to Galarneau (2005), as connections between elements of knowledge or knowledge and application. A distinct feature of the game context is that it creates a simulated practice (Henriksen, 2000), and thereby providing access to situations not normally available for the participant or for an explorative approach. Such practice can be seen as a constitution of a social system (in compliance with Salen \& Zimmerman, 2004), which from a constructivist perspective would consist of simulations of selected aspects of the mundane reality.

\subsection{The sphere of reflection}

The final of the three contexts is the sphere of reflection, which covers partly the mundane reality and the game context, as well as an area separated from both of them. The purpose of this placement of the reflective sphere is to illustrate that the reflective process is crucial in both understanding own participation in the different contexts, as well as seeing it as a process that is partly separated from the actions conducted in both contexts.

It also addresses a need for a reflective activity, which according to Høyrup (2006) implies a stop-and-think assessment of the hows and whys of own participation in a context, either in action, or in a retrospect. Another purpose of the reflective process is described with van Ments (1999), who uses it to clarify experiences and straighten out

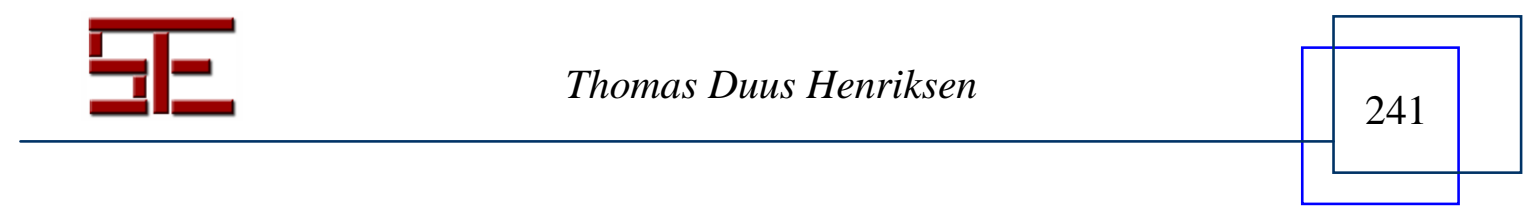




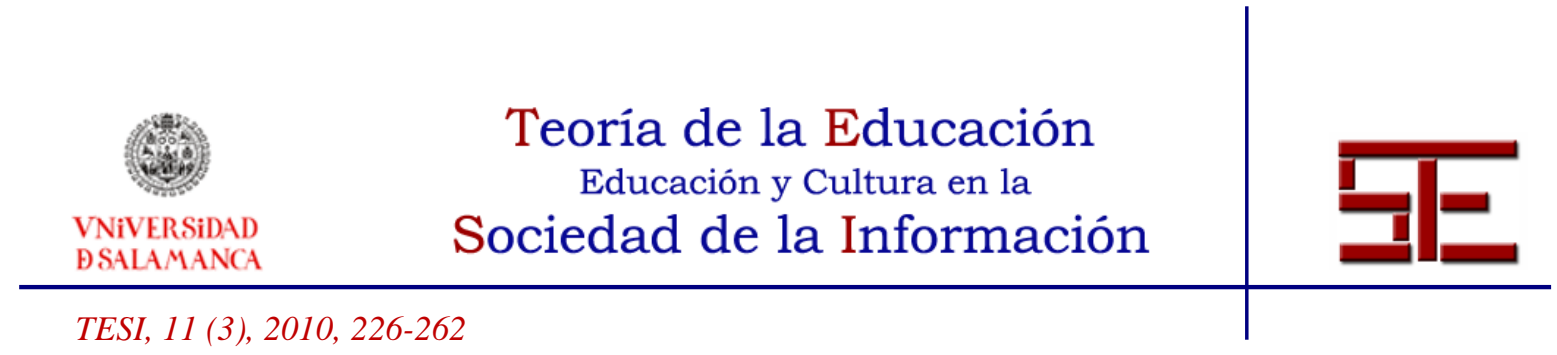

errors during the learning game, as they might, according to Høyrup, lead the participants to false learning.

Reflection is seen according to van Bolhuis-Poortvliet \& Snoek (quoted in Woerkom, 2003:40) /(Høyrup, 2006:88): "Reflection is a mental activity aimed at investigating one's own action in a certain situation and involving a review of the experience, an analysis of causes and effects, and the drawing of conclusions concerning future action". Similarly, reflection is seen as a conscious and voluntary effort to produce a higher understanding of the problem at hand, thereby stating reflection a conscious process.

Høyrup analyses the purpose of reflection from Merriam \& Clark's (1993) framework on learning. In doing so, he identifies a number of conditions for reflection, from which one key aspect can be seen as the separation through an inhibition and postponement of action. Another is an initiate definition of the problem at hand, why changes to the current approach is needed, as well as an integrative elaboration of ideas and feedback, thereby returning the learner with a higher level of understanding (Høyrup, 2006)

In the terms of Edgar Schein, the overall purpose of the reflective process in the learning game would be a) to create an unfreezing situation, b) to enable the participant develop, evaluate and refine experimental problem adaptational behaviour, c) to facilitate a refreezing integration of new and existing knowledge through attribution and identification of cause and effect, and d) to facilitate the transfer of knowledge between the different contexts of the game. Without the ability to transfer knowledge into the learning game, the role-play based approach would become superficial, and without the ability to transfer knowledge from the game to the mundane reality, the whole effort would become futile. The placement of reflective elements in the game is addressed further below.

To some respect, reflection can be seen as a contradiction to immersion; whereas immersion describes the processes of becoming engulfed in an experience, reflection implies taking one step backwards and thereby removing oneself from the immersion. It is in the interaction between the two that the combination of personal and character perspectives are combined and explored in regard to the efficiency of own vs. character skills, and it is in this immersion into a meeting between personal and character perspectives that a trap is set for producing an accommodative learning process.

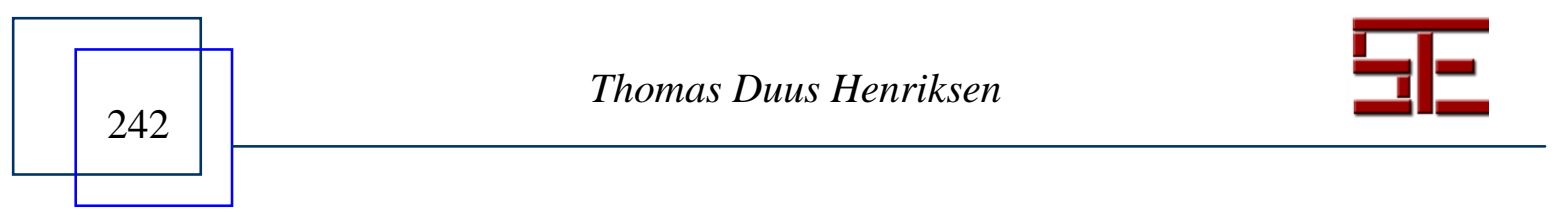




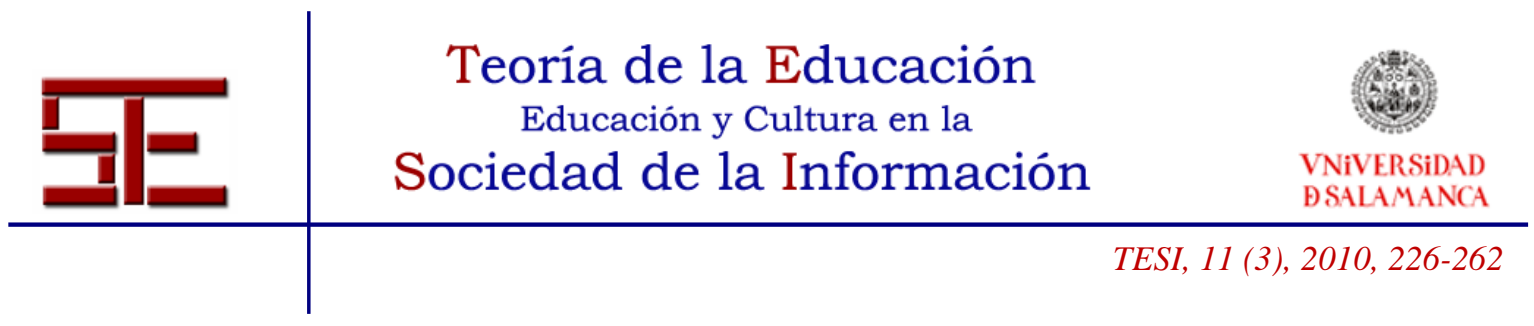

\section{0. - UNDERSTANDING ROLE-PLAY AND GAME-BASED LEARNING}

Whereas the purpose of the mundane reality in the model is to provide the game-based element with perspectives, the purpose of the game based element is to allow the participants to explore the viability of those perspectives to various problems through experimentation. The game will then, if well designed, provide the participant with feedback on the choice or application of perspectives, thereby creating an interactive learning setting. If properly framed, e.g. through an integration into a game didactic environment, reflective processes can be utilised to initiate and support, as well as making the benefit available to other contexts and situations.

A main quality of using role-play to facilitate this process is the plurality of perspectives put in play. Model 3 shows the 9 intersections between different areas of attention that becomes available through the role-play based approach, each representing a different approach or application of a perspective. These 9 intersections are attended below:

\subsection{Mundane Reality}

MP - The Mundane Person represents the application of knowledge in the participant's normal behaviour, based on own perspective in everyday contexts. This is also the application which the learning environments seek to change. This knowledge consists of the participant's beliefs, norms, values and understandings.

The knowledge represented here consists of the participant's schemata, including his or her norms, values, believes and understandings, which are utilised in order to comply with certain situations (Henriksen, 2002). These schemata may be more or less viable, both to external as well as the participant's own perspective, without necessarily being coherent. The stronger perception of viability, the more likely is it that the participant will allow these perspectives to dominate the construction of the role, as well as the participation in the game. There are many suggestions to why ill-adapted schemata are learned, which I will not address here. What is more important is that a vague reinforcement on adaptability can help maintaining such (e.g. as habits), which may function as a barrier for change.

In AGame, the personal mundane perspectives represent the daily praxis for the employmency workers, including their socially and culturally embedded approaches to and understanding of their work.

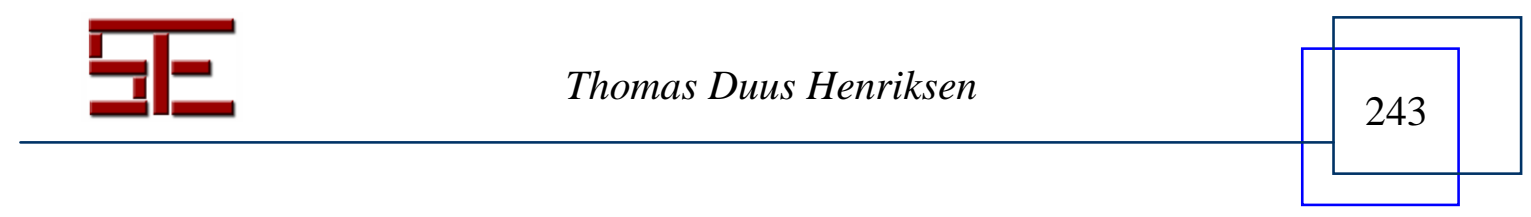




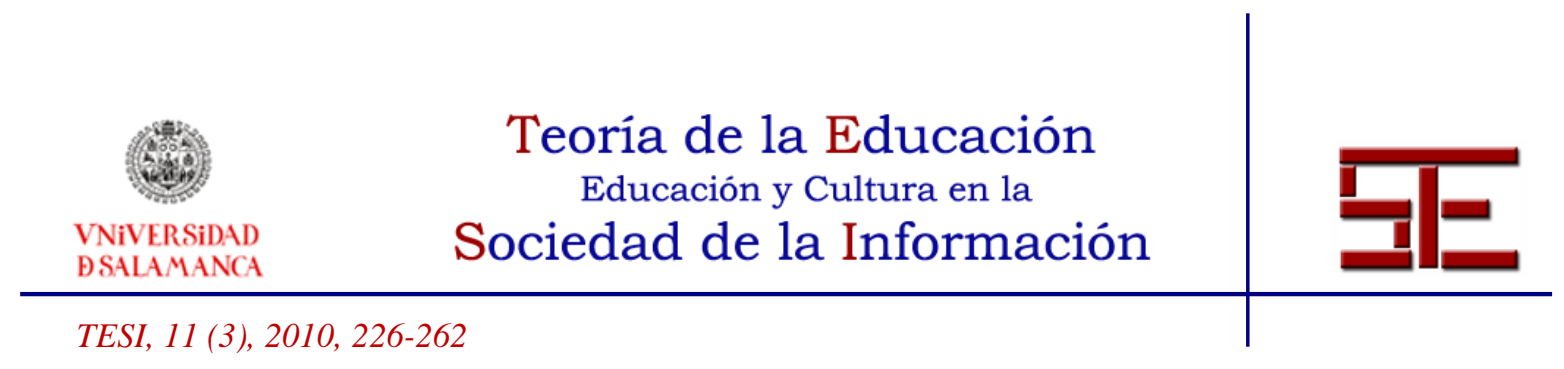

MR - the Mundane Role is an artificial perspective, based upon the participant's own beliefs (person) and the perspectives presented (character). According to the interpretative model (see above), the two perspectives are combined into an integrated perspective. This integration is usually determined by the personal perspectives, as the initial process consists of assimilation from the personal perspective.

The balance between the two is determined by the participant's willingness and ability to take on the role, ability to identify oneself with the character (Malone \& Lepper, 1987), the attractiveness of the fantasy presented (ibid), the use of primary (perspective adding) and secondary (perspective removing) fiction (Henriksen, 2004), and facilitation (van Ments, 1999).

The MR is more seen as a point of departure and a parallel bi-product than being an applied perspective in it self. It is a temporary construct, based on the communicated perspectives from the character used for forming an initial participation in the game. It can therefore be seen as a tentative construct which is tested through the game.

In AGame, the mundane role was a reluctant attempt to grasp the presented perspectives, seeing a demand for learning and using them, but also a resistance towards being forced to use something that seemed incompatible to their praxis.

MC - the Mundane Character represents the knowledge or perspectives presented by the learning environment, particularly the part that is to be further explored through the game. The collection of perspectives embedded the mundane character is an island of knowledge, which is not necessarily connected to any of the participant's knowledge. Such knowledge is often too cumbersome to be viable to the participant's complex reality, or it is somehow rejected for being too incompatible with existing perspectives (in contrast to perspectives that are able to initiate the energy consuming process of accommodation).

According to Ryan (1991), fiction is understood as differences from reality. In roleplay, this is typically done through the use of primary fiction, which adds perspectives and possibilities, and of secondary fiction, which removes perspectives and possibilities (Henriksen, 2002). Whereas the primary fiction is used for presenting new knowledge to the participant, the secondary is used for preventing or limiting the use of other knowledge - usually knowledge that normally would be available (e.g. personal knowledge).

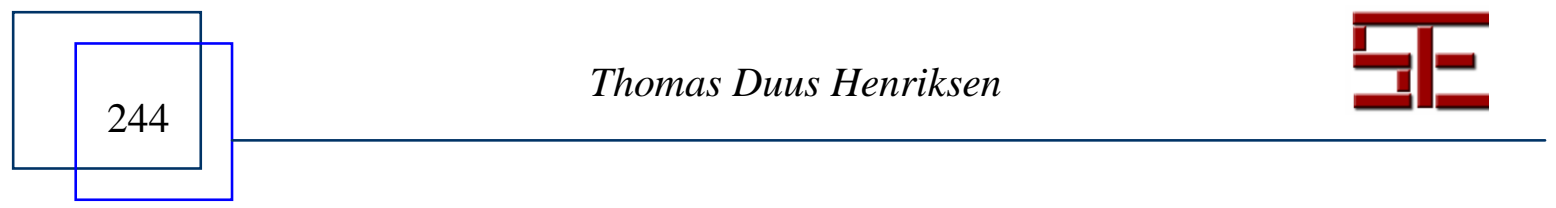




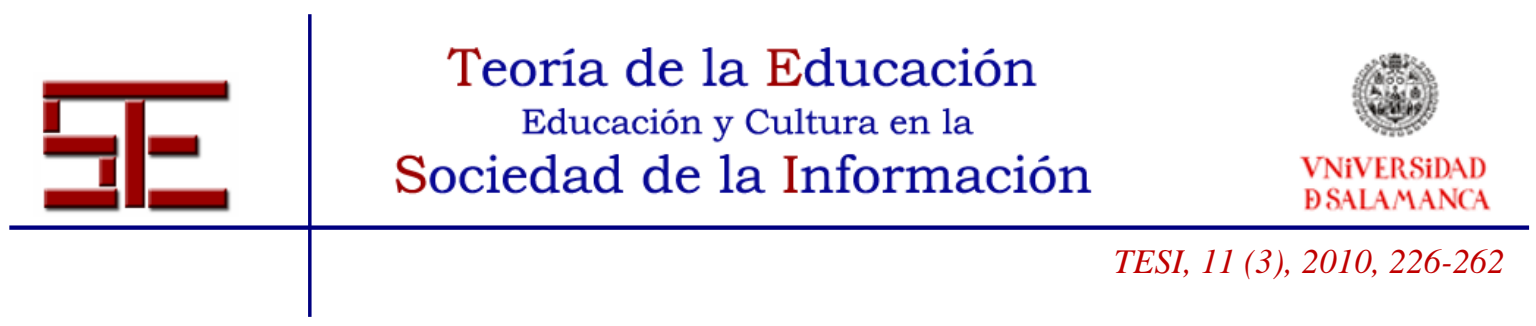

The character perspectives are usually defined by the game designer on basis of the learning objectives of the game, but if one prefers an existentialist approach, there is nothing preventing a co-creative process of character between the game designer, facilitator and participant.

In AGame, the mundane character perspectives represent the content of the presented reform, along with the tools and demands that it requires. This knowledge was generally perceived as overwhelming, impractical and incompatible with the complexity of the participants' work.

\subsection{Game Context}

GP - in Game situations, the Personal perspectives are seen where a) the participant is unable to link or utilise the perspectives of the character, b) rejects the perspectives of the character, or c) where the perspectives are insufficient to the problem at hand. The latter is especially relevant when attempting to facilitate learning based on Papert's (1996) constructionism, facilitating creativity, or when trying to build bridges between theory, existing knowledge and practical application (Galarneau, 2005).

Learning games based on role-play distinguish themselves here, as they allow the existing knowledge of the participant to be taken into consideration. These perspectives are to various degrees treated as barriers for change (as well as playing the role to the full) and therefore attempted drowned out through secondary fiction. If GP are applied to the learning game, chances are that the participant will miss the point of the game as personal perspectives may prove viable in the game. If this is considered a problem, it may be the result of a poorly designed learning game, or it may be a product of a too essentialistic approach to designing learning games.

If the learning game is to facilitate a change of perspectives (e.g. through an accommodative process), it is important to prove the application of personal perspectives wrong (or at least improper) in solving the problem of the game, thereby laying the grounds for creating the unfreeze manoeuvre. If the game based learning processes are to facilitate intrinsic motivation (Lepper \& Chabay, 1985), say for instance in Papert's (1996) constructionism inspired learning environment, the application of the personal perspectives should merely prove themselves insufficient in solving the task, encouraging the acquisition of more or new knowledge. The application of personal perspectives to the game problems can be seen as perturbations

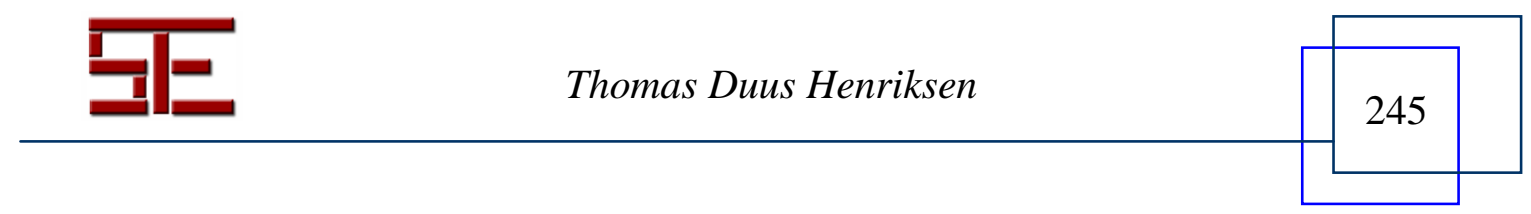




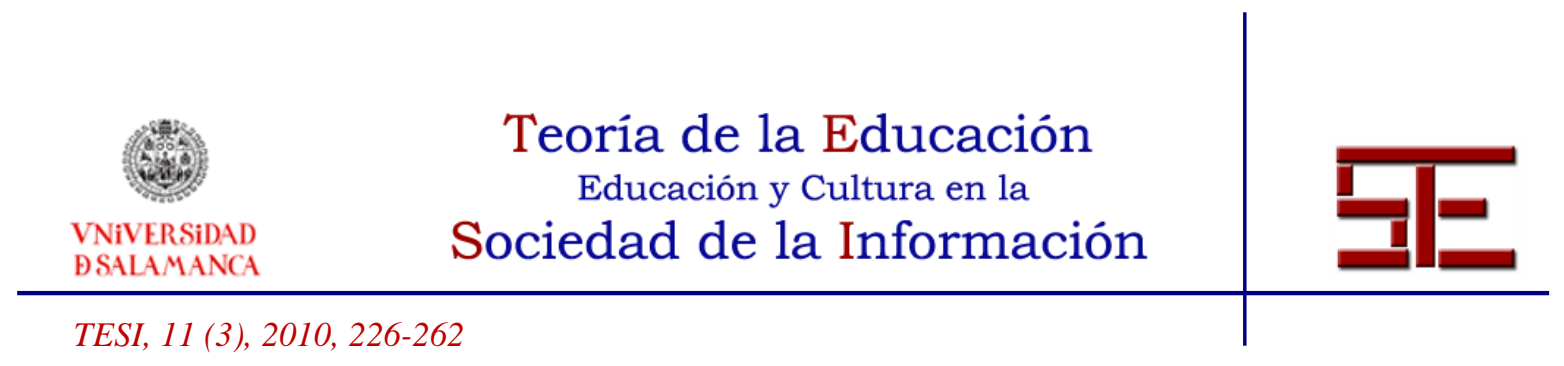

of the game, but can sometimes be utilised as valuable cues to making the game more true and realistic.

In AGame, participants often applied personal perspectives to the problems presented, and often doing so instead of using those of the character. Such approach has been interpreted partly as an attempt of non-completed learning, as resistance, but also an attempt to prove to the facilitator that current, personal perspectives were sufficient, rendering those of the character superfluous. Personal perspectives were also used for criticising the realism of the game, especially on lack of information, precision, etc.

GR - in the Game, the Role is present as the combined perspectives of the character and the person, applied to the game, allowing both to contribute with goals, values, knowledge, etc. to the combined perspective. This combination represents the perspective from which participation is taking place.

The two perspectives are applied in order to solve the problem of the game, but are at the same time in a constant struggle while attempting to prove themselves more viable to the problem than the other. If we allow ourselves to give the competing perspectives objectives, a goal would be to perturbate the other, thereby rendering it invalid to the problem or to itself. The balance between the two is determined by the learning objectives, choice of style and facilitation. Tipping the load towards personal perspectives would allow the participant to explore a problem setting from an existing perspective, aiding a cementation of those; tipping the load towards the new knowledge would demonstrate the effectiveness of such to a given problem, but would lack the integration with existing knowledge, eventually resulting in a rejection of the perspectives presented. Each would be relevant while attempting to facilitate either refreezing or unfreezing manoeuvres.

In AGame, the participants quickly realised that neither the tools represented neither by the character perspectives, nor their personal perspectives were sufficient in solving the task, resulting in combinations of the two. The tools were often countered by tricks and experience, forming basis for a creatively combined application of both.

GC - in the Game, the perspectives of the Character consists of representations of knowledge, which is more or less directly applicable to the problems encountered in the game. As the perspectives are placed in environments, in which they can effectively applied to current and relevant problems, they are most likely to be perceived as very

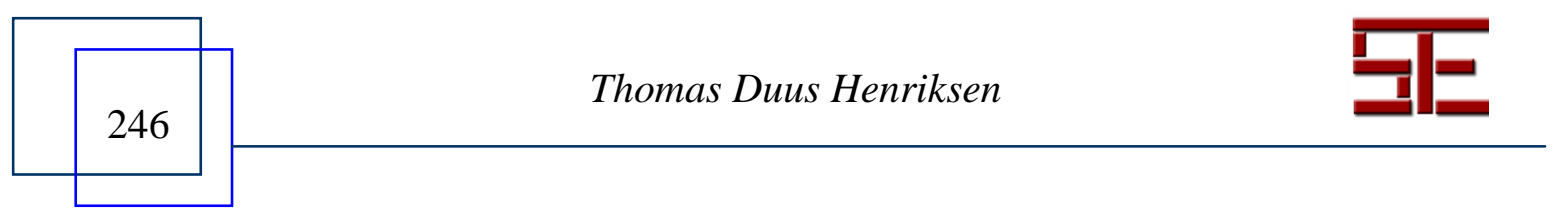




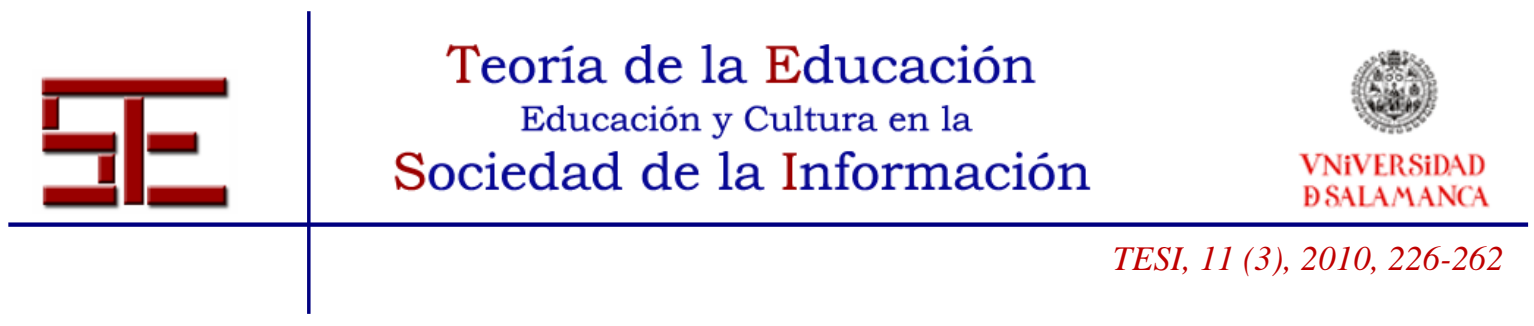

effective. The perspectives of the character become less cumbersome when situated in game, rather than the previously presented off-game presentation (MC).

When applied in the learning game, the character perspectives are in direct competition, not with the problems, but with proving themselves more viable in solving the presented problems. If the participants would fail in solving the problems, the character perspectives also fail in proving themselves viable.

In AGame, participants applied the character based perspectives onto the problems presented in the game, using the tools to quickly navigating around the presented problems. As the perspectives proved viable to the realistic simulation, acceptance of the perspectives was increased.

\subsection{Reflective Sphere}

RP - the Reflections on Personal perspectives are to help the participants in developing, testing and refining the adaptability of their personal perspective, but also to take a critical stance towards their efficiency. Such stance is relevant both to evaluating viability in the game, as well as in the mundane reality.

A major purpose of the reflection here is to evaluate the viability of different perspectives across different contexts, both in order to render some as insufficient, but also for the development and construction of new applications of personal perspectives.

In AGame, participants reflected on the viability of their personal perspectives across the game context and their mundane reality, finding both advantages and disadvantages. The participants were keen on maintaining their personal perspective, even while new knowledge proved just as useful, which was seen as an attitude against change.

RR - the Reflections on the Role has a triple purpose; first to play a part in the unfreeze in rendering existing perspectives insufficient, second to move to a viable combination of personal and character perspectives under the given circumstances, and third to utilise the refreezing process to bridge a transfer between the two contexts.

The reflections on the role plays an important part in the refreezing process, as they assist the participant in evaluating the viability of the applied perspectives, thereby

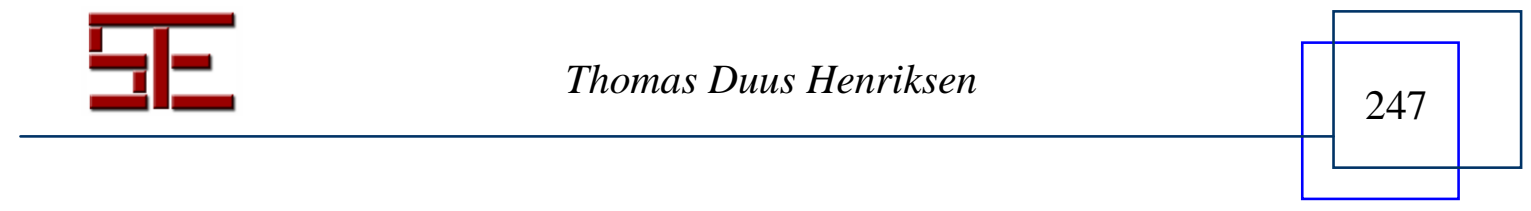




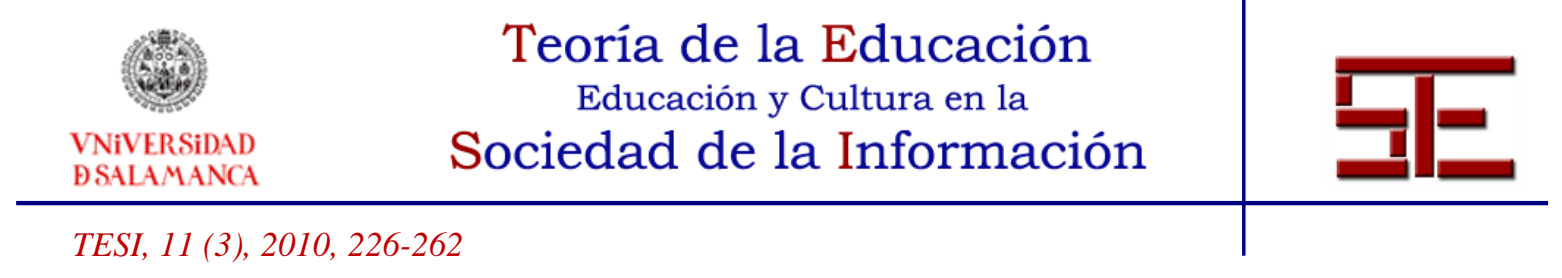

forming the basis of an integration of the new knowledge, experienced in a new setting, and the existing perspectives of the participant.

In AGame, the reflective combination of the character and personal perspectives was considered the major contribution of the learning game. It enabled the participants to integrate their existent knowledge with the presented knowledge, thereby combining the two to a new level of performance. Such integration proved helpful in both creating a new, integrated understanding of the field, as well as creating an approach, which could be transferred from the game context to the participant's mundane reality.

RC - the Reflections on Character perspectives are aimed at addressing the viability of the presented knowledge and perspectives across the different contexts and the problems presented by those contexts.

In AGame, constructive reflections on the character perspective is considered one major benefit from the game, as the participants gradually acknowledged the benefit of the perspectives of the game, but also that they gradually ceased attributing their success to game-contextual factors. The perspectives were considered beneficial to the game context, but were, through the reflective process, bridged to the mundane reality of the participants, thereby allowing them to perform a knowledge transfer between the two contexts.

To sum up, the structure proposes a process that encourages the participant to consider the basis of ones own agency, first in the game, and thereafter accordingly to the participation in mundane reality. Resistance is likely to be encountered towards the new perspectives. If this was not the case, teaching could be reduced to a communication across motivational and perceptual filters. The game context was utilised to produce new perspectives to both personal and character perspectives, utilising diverse reflective tools in order to facilitating both the formation of a new understanding, as well as a knowledge transfer to the mundane reality of the participant.

\section{1. - APPLYING THE EDUCATIONAL PERSPECTIVE}

A major issue of the process presented above is the essentialistic de-confirmation of the sufficiency of existing, personal perspectives and approaches to a particular problem. If this de-confirmation is not conducted, it is not likely that the participant will realise the

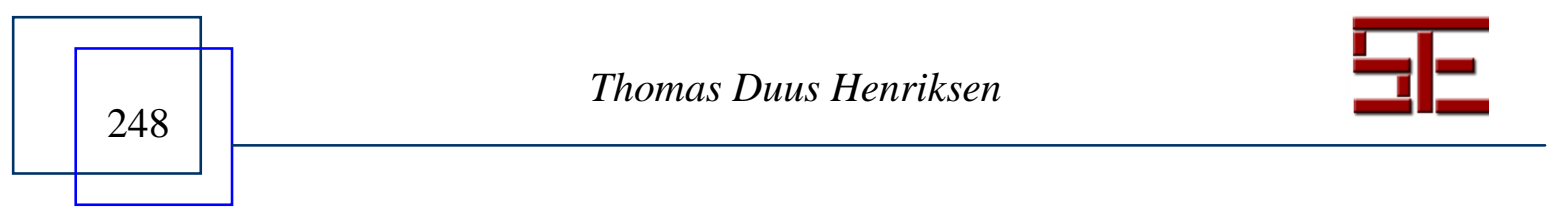




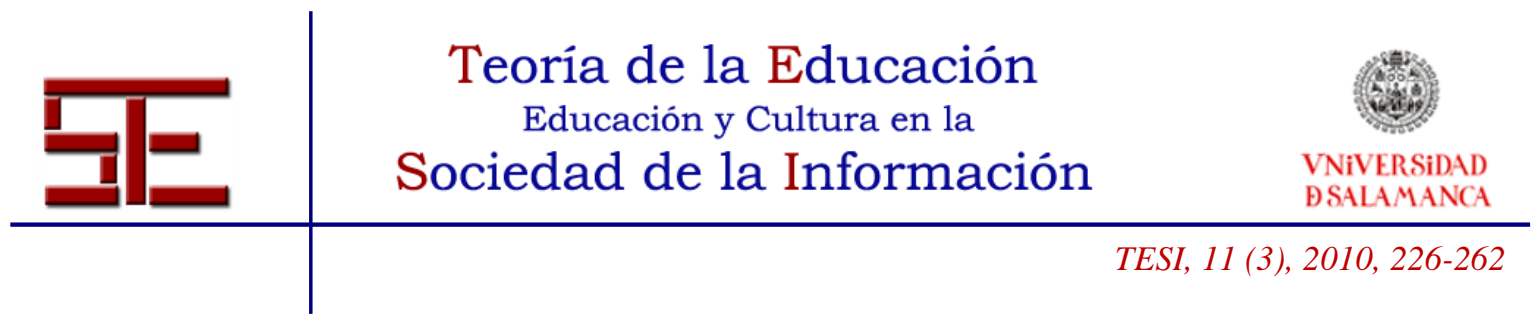

value of the perspectives presented, thereby reducing the motivation to learn this material.

Schein's concept of unfreeze-move-refreeze based learning is very applicable to such learning process. As Schein seeks to bring his students into facing and recognising the insufficiency of current knowledge or approaches, a similar approach is utilised in the above example in order to facilitate a shift of perspective, from the personal perspectives, towards those of the character. Such process is not motivated by entertaining the participant, but rather by utilising a goal-orientated incentive towards mastering the situation, rather than feeling insufficient to it. Such motivation combines intrinsic and extrinsic participational incentives, making it somehow difficult to place within the framework of Malone \& Lepper (1987). The overall motivation for participating in the educational role-play is obviously game-external, which points towards the extrinsic incentives. The role-play does, on the other hand, help us creating bubbles of intrinsic motivation by being able to actualise its problems to the participant. The desire to being able to master a situation is not limited to a cognitive desire for situational adaptation (von Glasersfeld, 1995), but is also likely to be fuelled by social incentives, especially if the task is considered prestigious to the participant.

In AGame, the participants were keen on proving the effectiveness of their existing knowledge and approach, either to the facilitator, to each other, or to themselves. As long as this perspective stood unchallenged, the new perspectives were rejected, but as soon as the unfreeze process had had its effect, the participants' eyes were open to its viability to the presented problems. The tools were then considered means for reachieving mastery in situation presented by the game.

\section{2. - THE PROBLEM OF REFLECTION}

The issue of reflection is addressed by Paras \& Bizzocchi (2005) as problematic when trying to maintain the magical circle or a state of flow. The problem arises as reflection encourages a critical view on the game based activity, thereby cancelling out the conditions originally used to produce the play-like state of mind. Reflection is, on the other hand, a crucial element in change learning: Without reflection to draw upon and evaluate game-external resources, a game-internal adaptation is produced, making the main benefit of the game an ability to play the game, which to the educational setting is not considered to be a desirable objective.

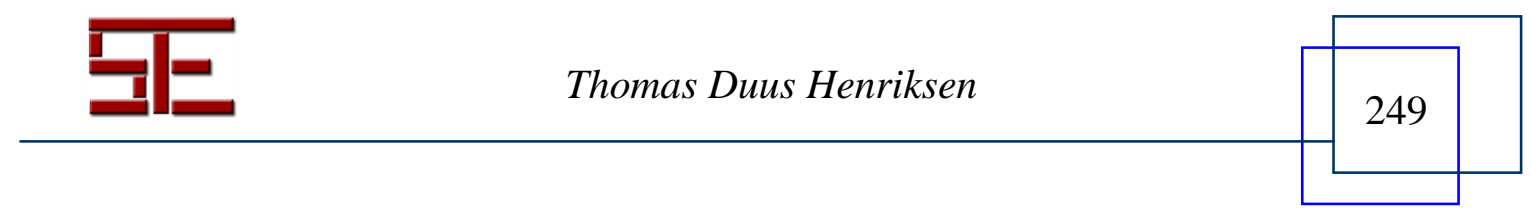




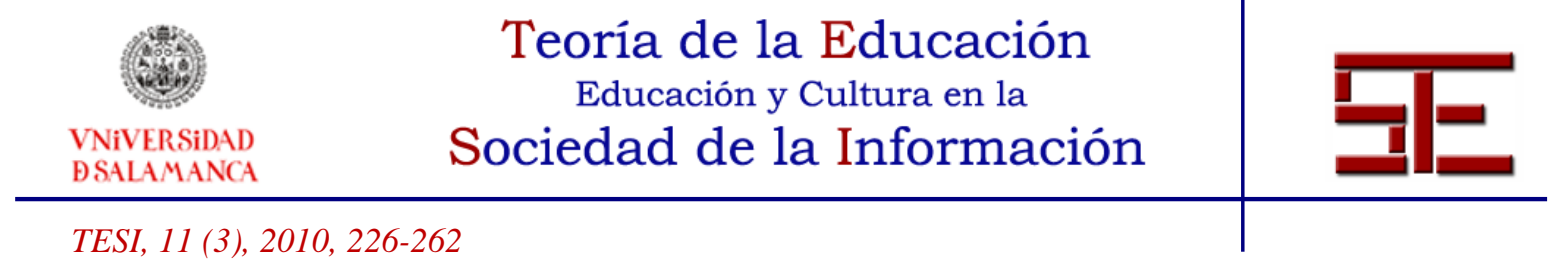

The reflective process is usually seen as a mean for facilitating transfer, making the conclusions of the game available to the mundane reality of the participants. One such approach is presented by van Ments (1999), using reflective processes to sum up and evaluate after a role-play (and thereby taking place outside the magical circle), thereby facilitating transfer. A somewhat different approach is offered by Paras \& Bizzocchi (2005), attempting to embed the reflectional process in the game itself in order to prevent the reflectional process in forcing the participant out of the magical circle.

Four placements of reflectional processes can be identified in learning games, each orientated differently in the game design, and each with its own pros and cons (see model 4):

\section{Model 4: Placement of the reflective element}

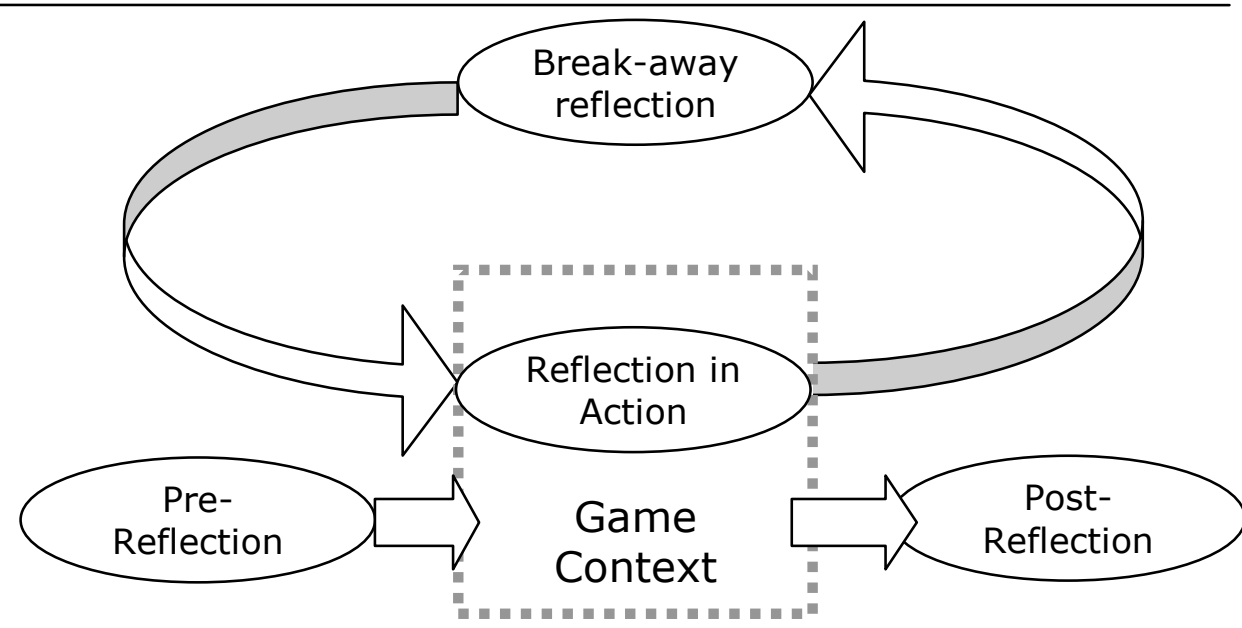

Pre-reflection covers the situation in learning games, where the game content is revealed to the participants before start, allowing them to plan their approach beforehand. The approach is usually seen within training environments where the participants are to train planning and execution.

The main consequences of this approach is that a plan is formed to be tested during the learning game, thereby framing learning games as experimental settings of simulated practice. The approach is limited by the need for an ongoing, evaluative reflection that allows corrections to be made to the plan during the game.

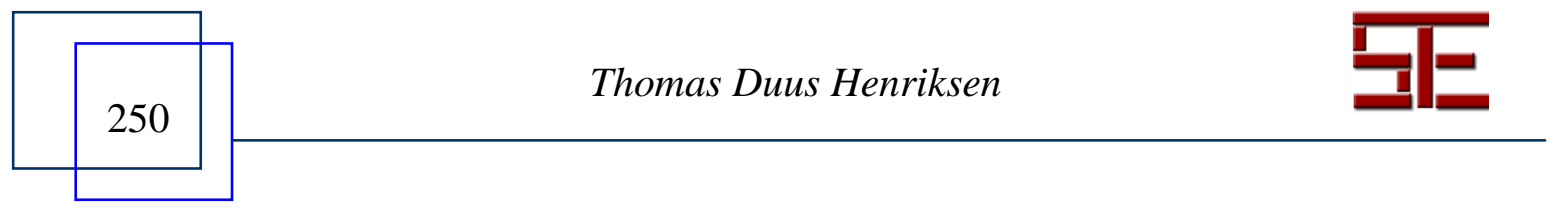




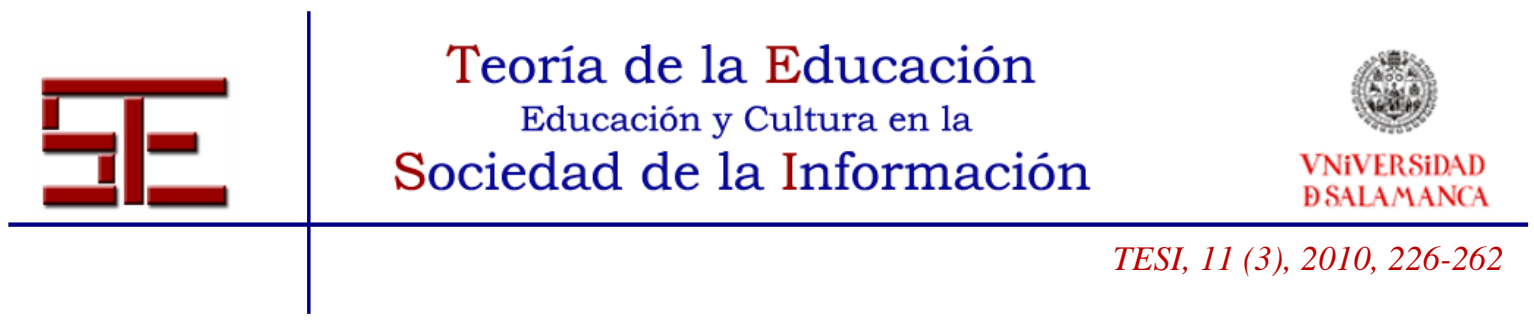

Post-reflection covers situations where the learning games is applied and completed, after which reflection is used to sum up events, evaluate and make the benefit transferable to other contexts. Such approach is recommended (if not seen as mandatory) by van Ments (1999), but has by some also been viewed as additional learning context.

The main consequences of this approach is that events and experiences of the game are reframed, shared and put up for discussion, allowing lines to be drawn from the game context to the mundane reality. The approach is limited by lacking an ongoing reflection, which would allow the participant in reaching higher levels of participation, performance and learning during the game.

'Reflection in action' was originally termed by Donald Schön (1983), and sought to produce an ongoing reflection, occurring parallel to participating in a praxis. The purpose is to embed a reflective process into the task at hand, allowing an ongoing adaptation and development to a context or a problem. Such an approach is suggested by Paras \& Bizzocchi (2005) while attempting to find place for the reflective process by embedding the reflection as an endogenous game process without breaking the magical circle. A means for facilitating such reflection is by embedding reflective phases into the game mechanics. An example is by using shared perspectives and goals, allowing group-based participation, thereby opening a room for discussion and shared reflection within the game.

The main consequence of this approach is that it allows an ongoing adaptation to the context or problem, thereby forming basis for improving the benefit. A main limitation is caused by the high demands placed upon the game design when trying to build endogenous game mechanics into the learning game (addressed by Habgood et al., 1995). It seems evident that an ongoing reflection will facilitate more adaptive behaviour in the game, but it is questionable whether it would affect the overall benefit of the learning game.

Break-away reflection is produced in game-pauses, asking the participant to stop and reflect on participation, strategies, goals, etc. The purpose is to give the participant new perspectives on his current participation. Break-away reflection is almost certain to break the magical circle, and should be used with caution in learning games. To my experience, break-away reflection often triggers irritation ("we were doing so well until you interrupted us"), or are simply ignored by the participants. Another likely event is

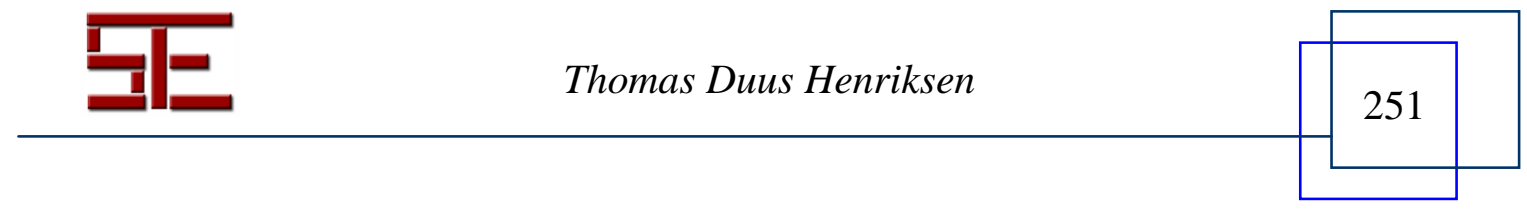




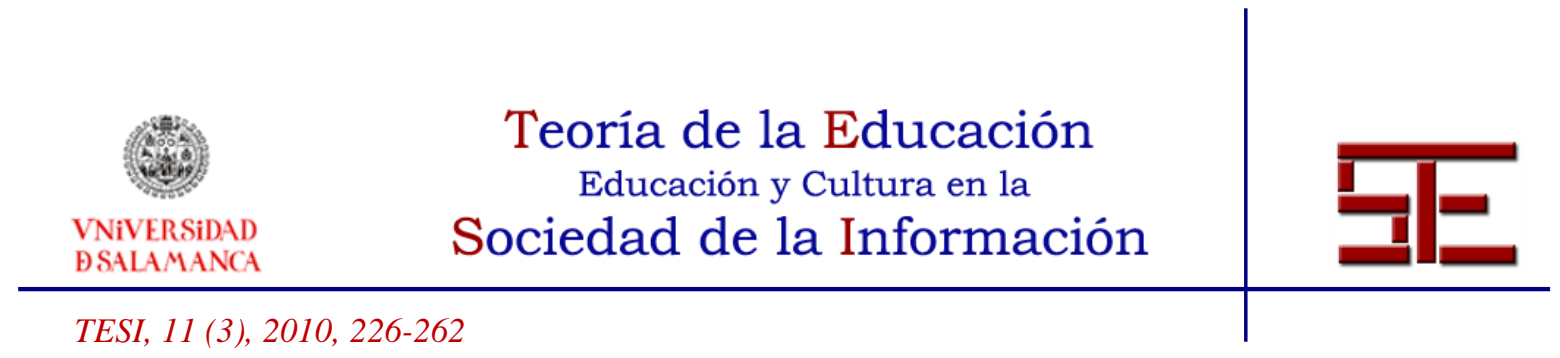

that participants seek to get the reflection part done and hurry back into the game. This is often seen when a participant encounters the learning element in a classical edutainment and hurries back to the game element.

The main consequence of this approach is a reflection upon current participation. The approach is limited by breaking the magical circle, and eventually producing irritation among the participants. The approach was however successfully applied during AGame, where it was used to focus the use of certain tools and perspectives, thereby promoting the use of the character perspectives.

The different approaches can be utilised to meet different purposes in the game based learning setting. The main contribution of such different approaches is that it allows us to implement reflective processes several places in the learning environment, creating a foundation for a combined approach. The different approaches are likely to yield different results, dependent on the used participational incentive; whereas the use of break-away from an entertaining circle of magic will produce an irritating sense of contrast, the same approach to a learning game based on social, goal orientated or frustration inducing incentives, the breakaway is likely to have a different effect.

The main concern for the implementation of reflective processes in learning games is to prevent them from undermining or disturbing the participational incentive.

\section{3. - GOING BEYOND FLOW}

The combination of Schein's theory on learning and the interpretative approach to roleplay offers an approach to considering the role of the reflective element of the learning game. The question is then whether embedding the reflective element into the game is desirable, dependent on what emotional experience the game is supposed to facilitate with its participant.

As previously mentioned, games are often brought into the educational setting for their ability to engage and motivate its participants, seeking to produce an immersive, entertaining and attention consuming experience to its participants. This inclusion of games is often based on an analysis and a design based on Csikszentmihalyi's (1975) concept of flow, which is widely seen as an aim for the game based learning experience (Habgood et al., 1995; Koster, 2005; Paras \& Bizzocchi, 2005; Prensky, 2001). As Prensky puts it "In Digital Game-Based Learning, one of the biggest challenges is to keep the players in the flow state in the game and in the learning simultaneously; no easy task, but enormously rewarding when successful.” (2001:125). However, when

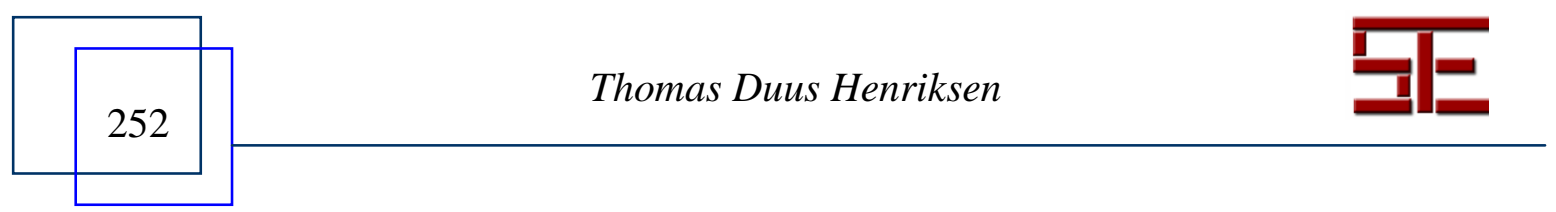




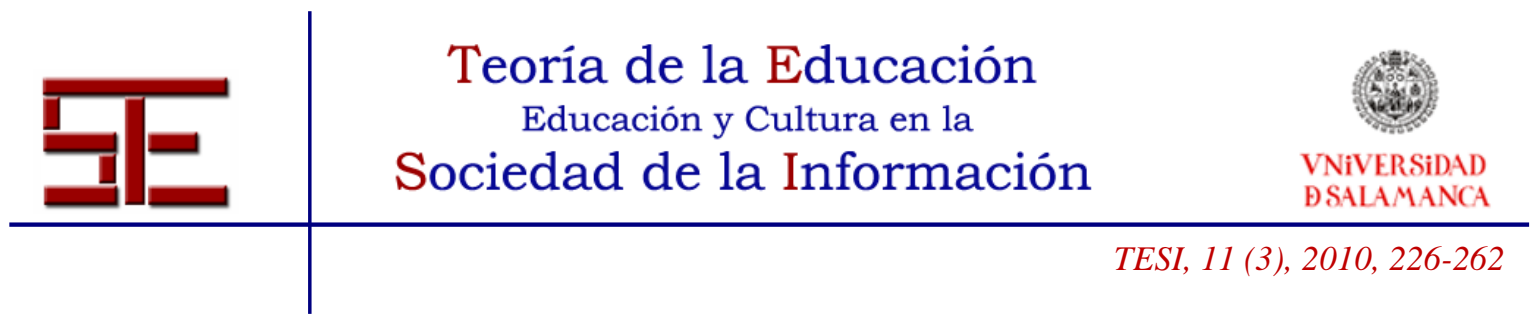

reading Csikszentmihalyi's conditions for flow, they seem less productive in producing learning environments to meet with certain learning objectives: "a sense that one's skills are adequate to cope with the challenges at hand, in a goal-directed, rule-bound action system that provide clear rules as to how well one is performing. Concentration is so intense that there is no attention left to think about anything irrelevant, or to worry about problems. Self-consciousness disappears, and the sense of time becomes distorted."(1990:71). Reflection is, on the other hand conditioned by an ability and opportunity to stop and think about the hows and whys, as well as being able to postpone action, quite contrary to flow, as the participant here is encouraged to perform to the maximum of his or her capability, effectively preventing the participant from postponing action.

The problem arises when focus is shifted from learning to performing, when attention is narrowed down to only focussing on the given task, letting out self-consciousness and problem external perspectives. To Maturana \& Varela (1992), reflection takes place outside the domain of production, claiming that performance demands will inhibit reflection. Reflection is thereby inhibited by the flow state, an important point noted by Paras \& Bizzocchi (2005:6). To the reflective process required in the presented model on game-based learning, an ability to reflect on the viability of diverse and combined perspectives is crucial, as well as a sense of self-consciousness in order to bridge the presented with the personal. This makes it pretty obvious that flow is not a desired state when facilitating change or reflective processes.

When attempting to facilitate reflection based learning processes, the flow state itself is undesirable in regard to meeting such objective. However, Csikszentmihalyi's model proves valuable for analytical purposes, as well as his observation that when we strive towards the various flow states, which are seen as in the span between skills and challenges, we are striving towards a state of mastery in regard to the task or problem at hand. In order to produce the basis for facilitating reflection, the learning game must seek to place its activities outside the flow area of the model. In addition, the flow area can, according to Csikszentmihalyi's theory, be considered to be a magnet, which pulls its towards it. If the combination of Schein and the interpretative model is analysed from within the flow framework, the participants would experience a combination of staging and solving activities, forming a stairway rather than a line based trajectory. This is illustrated in figure 5:

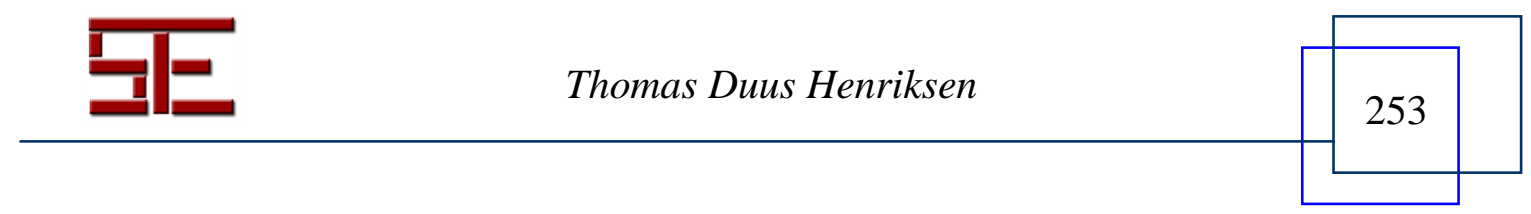




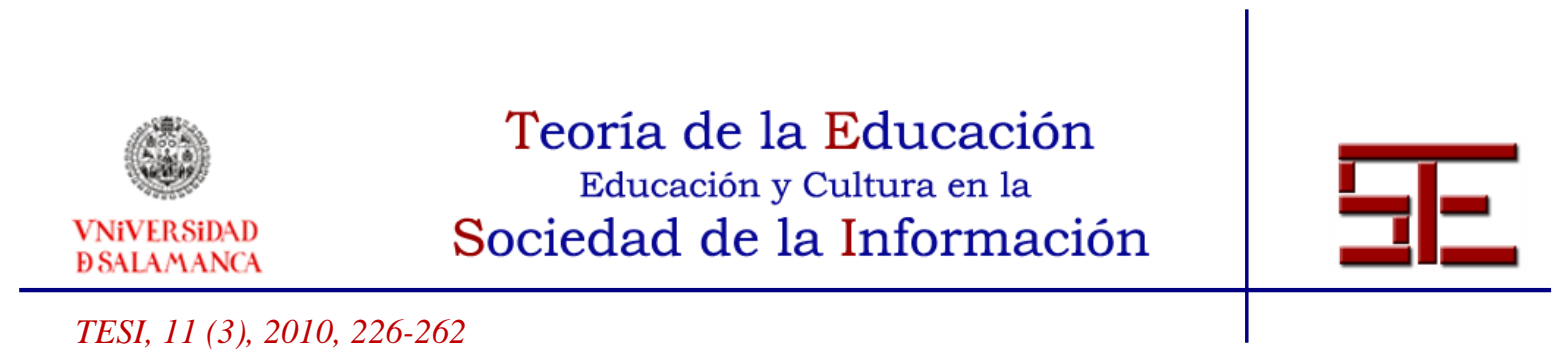

Model 5: The Stairway

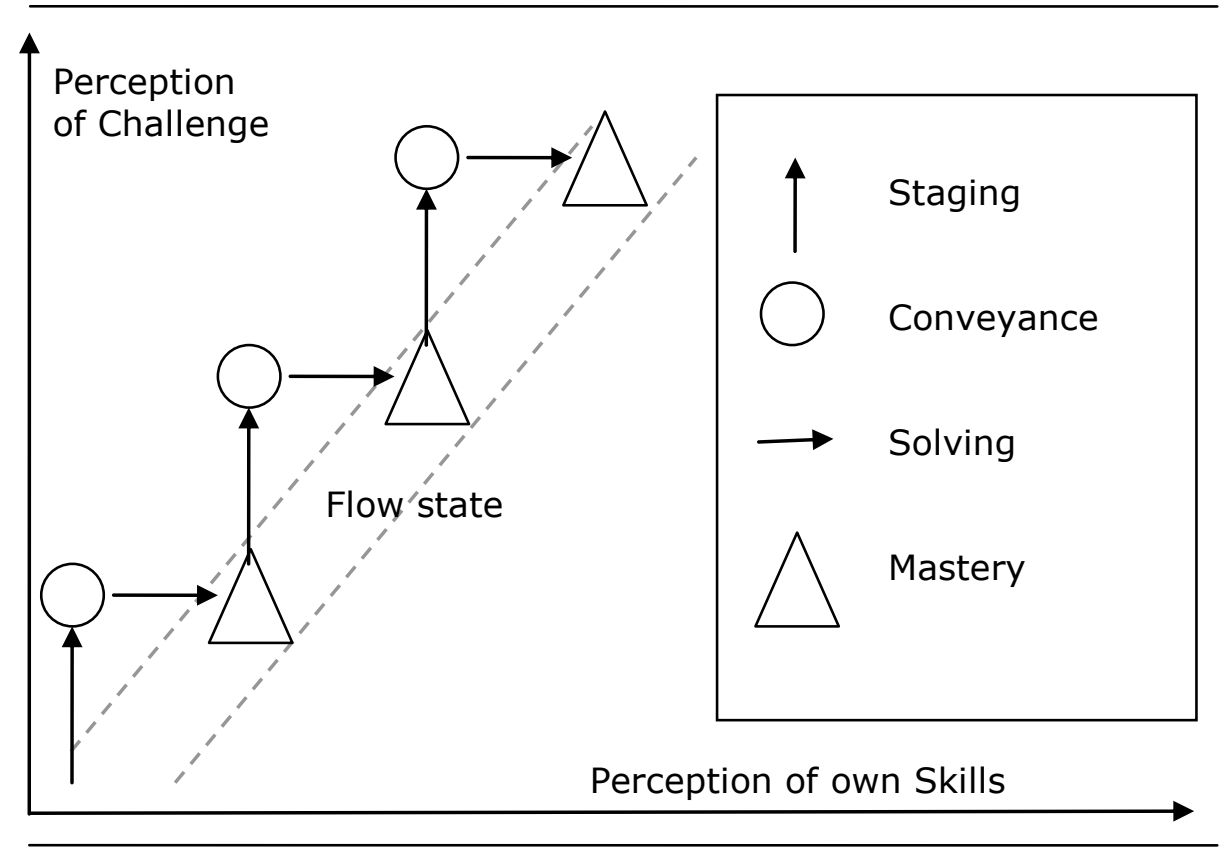

The stairway consists of two activities and two experiences, produced by the activities described below.

\subsection{Staging and Conveyance}

The staging process is the process that allows the participant to immerse into the magical circle of the learning game. By accepting and acknowledging the problems and values of the game, these become current and relevant for the participant to solve (Henriksen, 2002). Such process is described with Huizinga (1950) as the suspension of disbelief.

The main purpose of the staging is to pull the participants into an acceptance of the relevance of the game content, and in particular its proposed problems. This is done through the use of various incentives, e.g. competition, fantasy or social incentives, enabling the game to stretch motivation beyond those activities that are immediately entertaining. The staging incentives can be used for making the participant see and

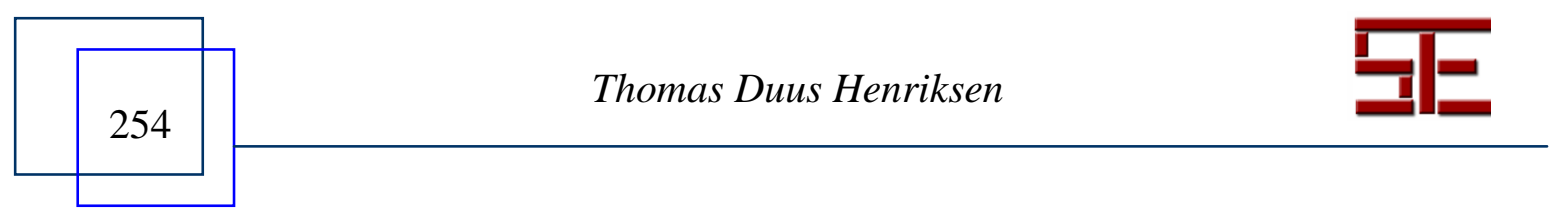




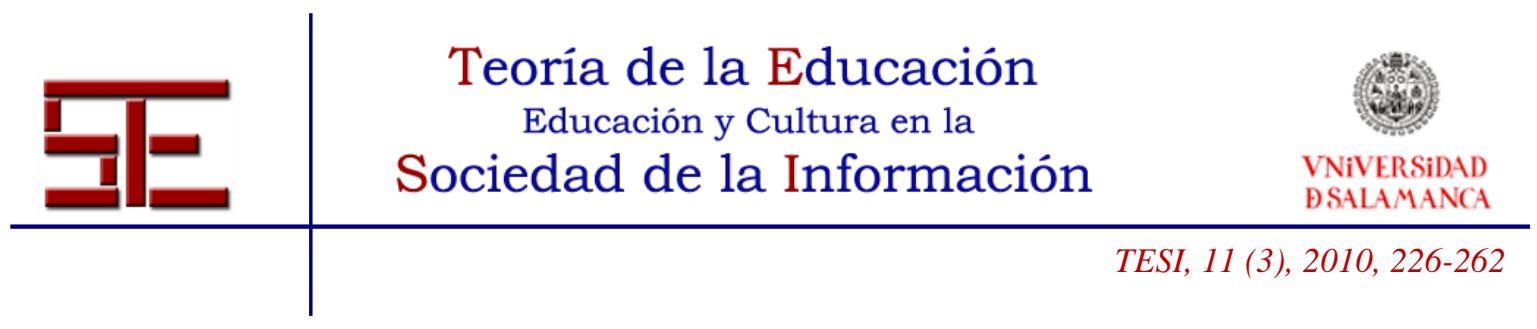

accept the importance of a task beyond current ability, which from the flow-perspective would frame the activity as anxiety producing.

The result of the staging process is to place the participant in a situation, that is a) unsolvable from current knowledge, and b) consisting of problems that are perceived as current and relevant for the participant to solve. Such span between own abilities and the desire to solve the current problem is likely to be perceived as frustrating, as well as creating a desire to eliminate the frustrating element. 3 strategies are available to the participant; one is leaving the set, the other two approaches to handling such stress can be seen with Lazerus \& Folkman (1984), who suggest either an emotional or problemfocussed approach to handling such frustration. Whereas the first and the second seek to eliminate the frustrating element, the latter seeks to address the lack of ability to solving the presented problem, thereby addressing the conditions that produce the stressful experience. If the staging fails to immerse and encourage its participant, a problemavoiding strategy is likely to be applied, whereas a successful staging will encourage the participant in solving the task. The result of a successful staging is an adaptive desire to master the frustrating situation.

Malone \& Lepper (1987) presents several incentives that can be utilised as a successful staging, e.g. competition, fantasy, curiosity or social desire, whereas a combination of curiosity and fantasy is suggested by the literate Brooks (1992), framing the desire for the story as a powerful incentive. The use of narrative desire can in particular be seen in the game Homicide, where participants are given bits of a crime story, which encourages them to solve several tasks in order to gain more bits of the story.

At the end of the staging process, conveyance takes place. The cause of the story is handed over from the staging events to the participants, allowing them to define their task at hand and then start the solving process. The extend of the conveyance is dependent on the task; solving a simple piece of math implies a small conveyance, whereas conveyance plays a major role in Papert's (1998) constructionist games.

In AGame, the participants were staged in a situation, which was relevant to their prior education and current job, giving them a social incentive to solve it. Being able to solve it was expected from them. The frustrating part was the new tools, encouraging several to refrain from taking an active part, whereas others accepted the staged importance, taking on the task. Before solving the presented challenge, the participants defined their task, planning what information and what positions to obtain through the game activity.

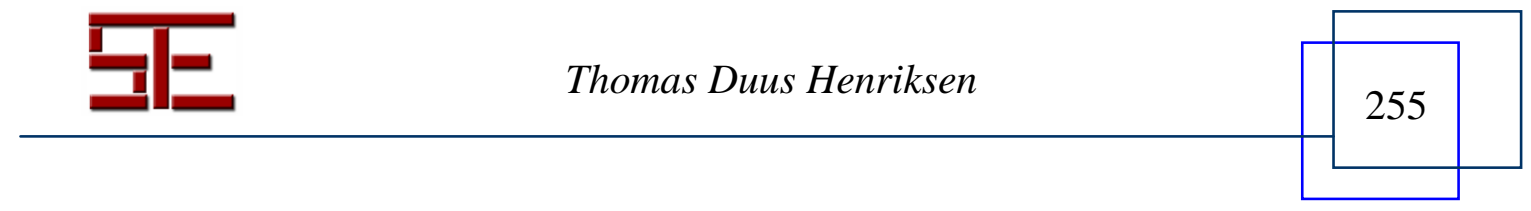




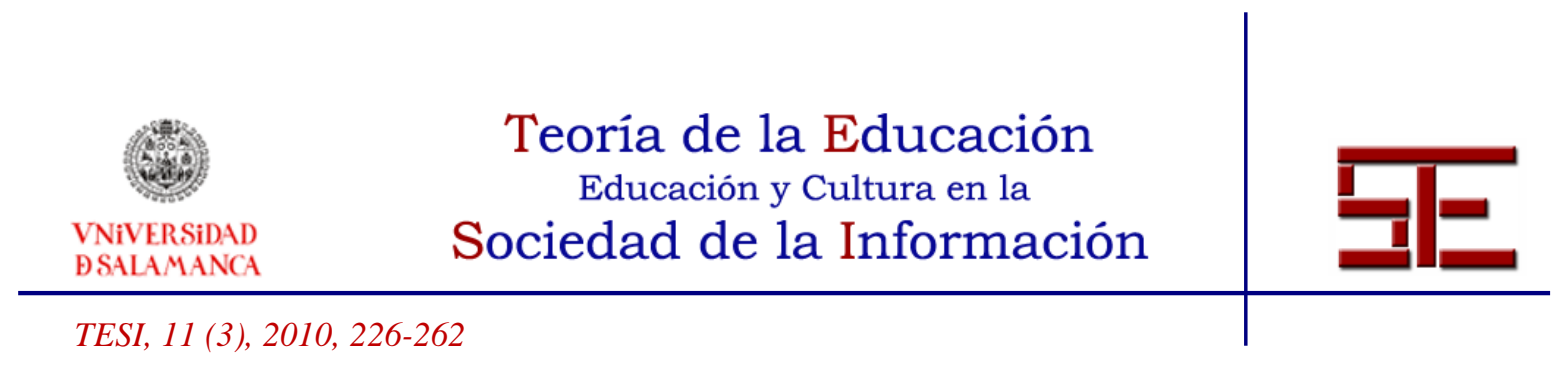

\subsection{Solving and Mastering}

The solving activity consists of the participant's effort to solve the presented problem, utilising whatever means made available by the game to solve the task. This could for instance be embedded knowledge, presented character perspectives or personal perspectives. During the solving activity, the game can present specific content to be learned, or it can use its mechanics to provide the participant with feedback on choices, decisions or actions. The experimental application of knowledge during the game is often considered the main learning activity in the game.

Participation in the solving task is driven by the previous staging effort, as well as an experience of moving closer to solving the staged problems. One significant driver is the actual solving of current problems, producing a sensation of mastery (Malone \& Lepper, 1987). This sensation of mastery would according to Csikszentmihalyi's (1975) theory when the participant experiences that his or her skills meets the challenges, which may allow the participant to move in to the emotionally rewarding flow area.

In AGame, the solving activity consisted of a staged assessment task, applying the various tools onto the process. A sensation of mastery was achieved either through positive feedback from the game, or through the succeeding evaluation.

The two presented processes each contribute to the same process, but differ in several ways; whereas the staging is produced by the teacher or facilitator, the solving task is performed by the participant. Another important difference lies in their challenge; the challenge of staging lies in creating an interesting game, whereas the solving part depends on the designer's ability to turn the setting into a problem-embedded learning game.

In AGame, only one phase of staging and one of solving was employed. The situation was staged, and then solved. In Homicide, several of each stage was employed, thereby forming the ladder displayed in model 5. The difference in educational benefit from the two approaches, as well as the effect of the size of the step is a matter of further study.

\subsection{Summing up}

To sum up on the perspectives presented, the main consequence for considering nonentertaining participational incentives in learning games is that they unlock new uses for learning games. Rather than being a tool for simple drill-and-practice learning

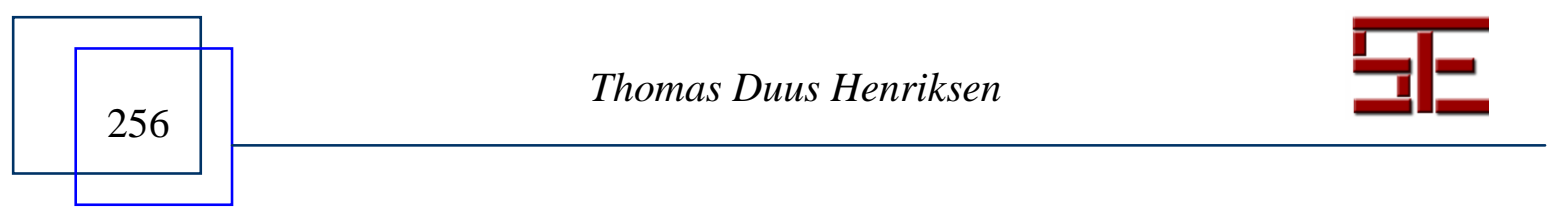




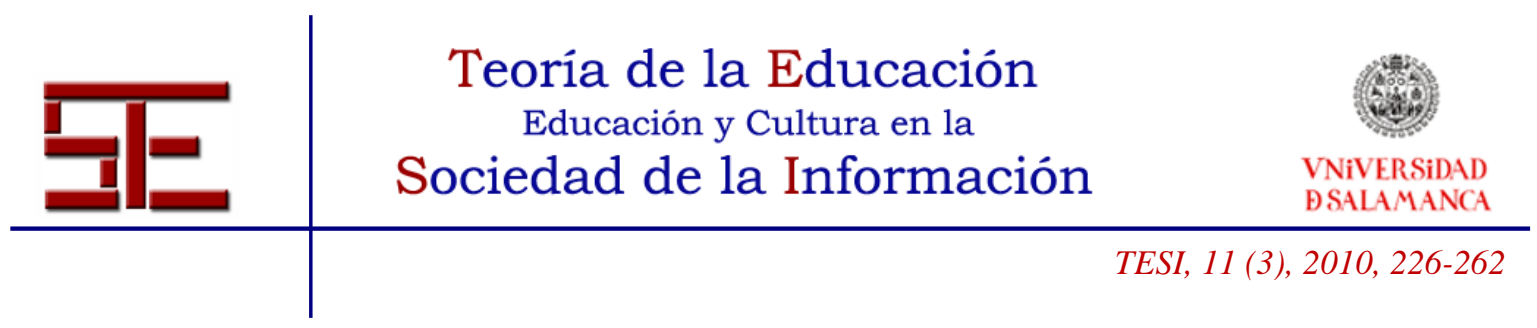

situations, learning games can be used for facilitating advanced learning processes, such as change learning and other reflection based processes. Especially the role-play based approach to game based learning seems fruitful, as it allows the learning process to take the participant's existing knowledge or practice into account, thereby tailoring the benefits to meeting the specific demands of each participant. It is important to notice that the entertaining approach cannot cover all learning purposes.

\subsection{Participational incentive, feedback mechanism or content provider?}

A key issue in utilising learning games for advanced learning processes, is to integrate its ability to provide participational incentives and its ability to provide content and feedback mechanisms. Participational incentives must be adapted to the learning objective, and thereby to the content, as well as the participational incentives must be embedded in the content.

\subsection{Games as providers of participational incentives}

As mentioned earlier, there is a tendency to think games as providers of participational incentive, either by making the learning experience entertaining (see e.g. Gee, 2003; Konzack, 2003; Koster, 2005; Prensky, 2001), producing various emotions connected to fun (Habgood et al., 1995; Koster, 2005) producing various states of flow (Habgood et al., 1995; Paras \& Bizzocchi, 2005). The model presented above, which attempts to combine the interpretive model with Schein's (1962) Unfreeze-Move-Refreeze, is utilising a somehow reverse approach to facilitating participational incentive. Whereas entertainment, fun and flow seek to produce a pleasant experience to the participant, using this pleasure to maintain participation, the approach presented in this article seeks to induce a more unpleasant emotion into the participant, using our natural tendency to avoiding such experience for creating participation in a learning process. Such frustration based learning processes might not seem that charming, but are actually rather common in learning settings, e.g. as fuel in goal-orientated learning settings or in competitions. The integration of participational incentives calls for an understanding of how games are designed.

In AGame, frustration arised as the current, personal, but also desired perspectives proved insufficient in solving the task at hand. The provided character perspectives could then slowly be added to an experimental process, in which they were explored by gradually being applied to the problem and evaluated accordingly. In this situation,

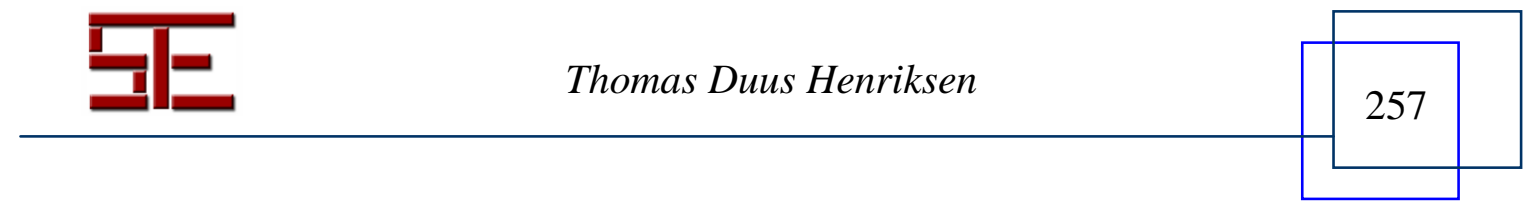




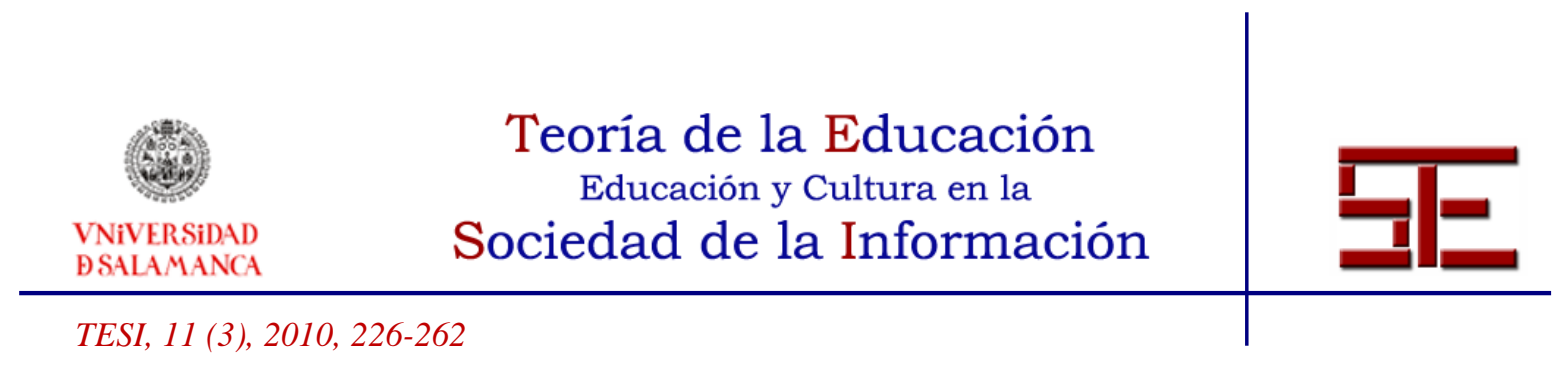

frustration worked as an incentive for testing the new perspective instead of applying the usual (and desired) perspective.

\subsection{Games as feedback mechanisms}

A more content related use of game based learning is the element of feedback in order to help the participants in evaluating their efforts. The game must provide the participants with feedback on the success of actions and strategies employed, thereby allowing the participant to experiment through perspective application and viability reflections. Such integration calls for a close integration of game-design and learning theory when designing game-based learning processes.

In AGame, feedback was provided through the reactions of other participants. If a tool was successfully applied, it provided the participants with new information, which would bring them further to their goal of performing a correct assessment. Unsuccessful application merely produced useless information at the cost of time. To the experienced employmency workers, such information could easily be interpreted and used as a progress-measuring score in the game.

\subsection{Games as content providers}

Games seem inferior to many other learning environments in communicating static, knowledge or perspectives (Henriksen, 2004), but seem useful for learning processual knowledge, such as application, integration and such. Habgood, Ainsworth \& Benford (1995) recommend embedding the content to be learned into the core mechanics of the game itself, thereby ensuring that the mere participation in the game provides the participant with exposure to the content of the learning game. A rare example of such an endogenous integration of content into a game mechanics is provided by Homicide (Drabssag/Melved), in which the participants solve science tasks (e.g. conducting a gunpowder analysis) in order to solve the game. Such integration calls for a thorough understanding of the content stated by the learning objective.

In AGame, the tools provided by the character perspectives constituted the content, thereby embedding the content in every single attempt of acting or applying the tools in the game. These character perspectives were provided by the National Labour Market Authority.

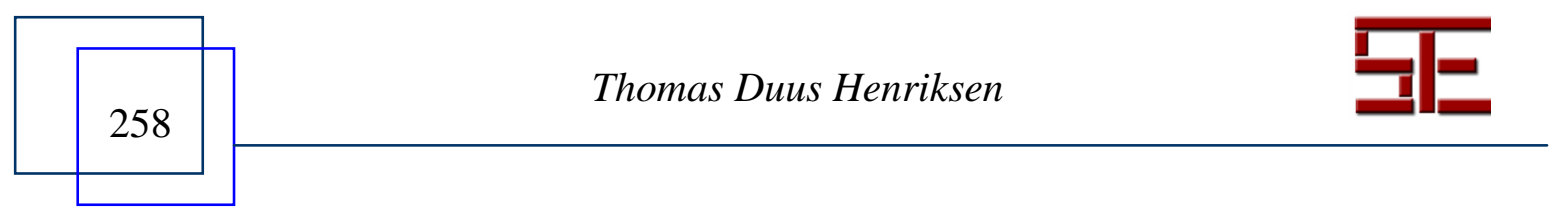




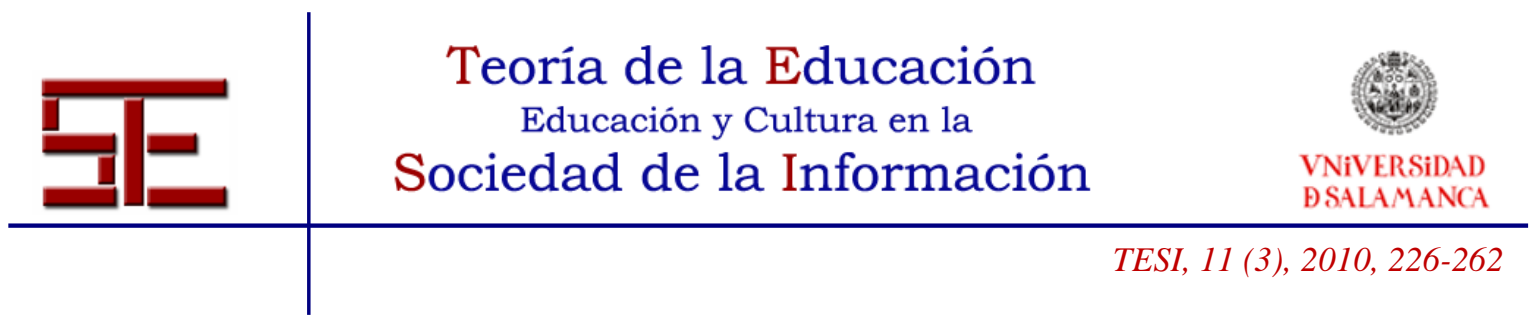

In order to complying with these three areas of attention, a broad call for competencies is needed in order to design an effective learning game. Providing the participational incentives calls for the game-designer, whereas the implementation of feedback mechanism and other means for facilitating the learning process calls for learning theorists or for a didactic frame for learning games. Finally, the orientation and qualification of the content of the learning game calls for a specialist within the given area.

\section{4. - CONCLUSION}

If role-play based learning games is to meet its full potential within educational settings, there is a need for an innovation of the common understanding of games in order to set users and designers alike free of the assumption that such games should be entertaining. This calls for a tremendous work, not only to provide designers with the proper tools for designing such games and designing them, there is also a call for a marketing effort to eliminate the entertainment assumption among those who use and order learning games.

\section{REFERENCES}

Brooks, P. (1992). Reading for the plot: Design and intention in narrative. Cambridge: Harvard University Press.

Csikszentmihalyi, M. (1975). Flow. The psychology of optimal experience. New York: Harper \& Row.

- (1990). Flow: The psychology of optimal experience. New York: HarperCollins.

Egenfeldt-Nielsen, S. (2005). Beyond edutainment: Exploring the educational potential of computer games. København: ITU

Galarneau, L. (2005). Authentic learning experiences through play: Games, simulations and the construction of knowledge. Paper presented at the Digital Games Research Association (DiGRA), Vancouver, Canada.

Gee, J. P. (2003). What video games have to teach us about learning and literacy. New York: Palgrave Macmillan.

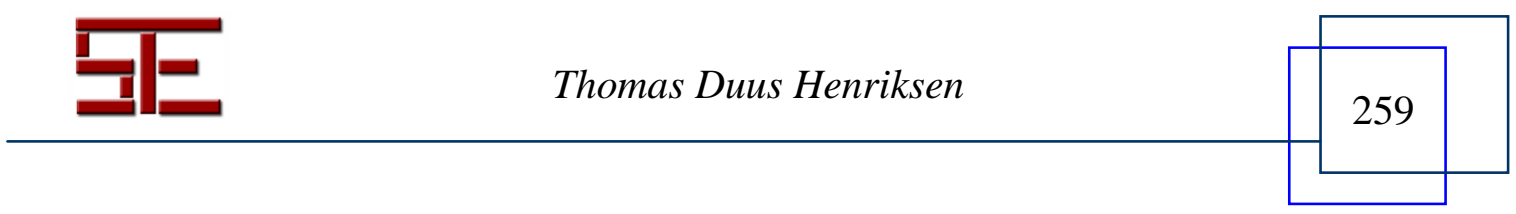




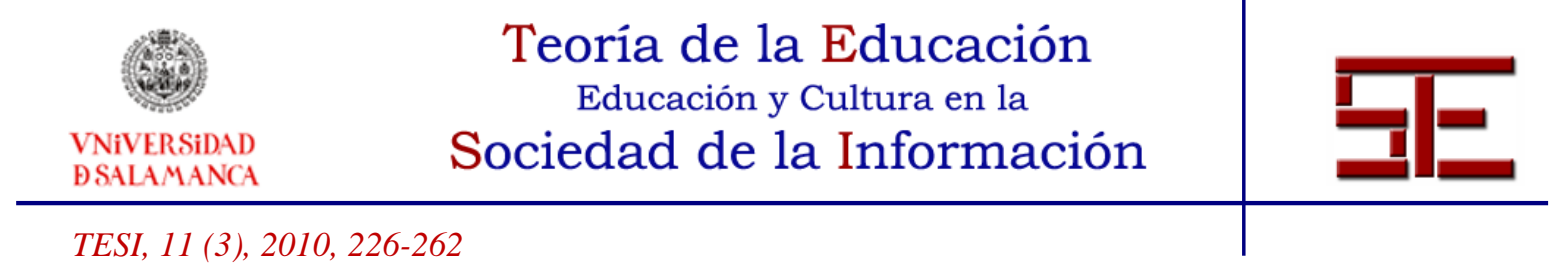

Gregersen, F. (2003). Structuralisme. In F. Collin \& S. Køppe (eds.), Humanistisk videnskabsteori (pp. 199-224). København: DR Multimedie.

Habgood, M. P. J., Ainsworth, S. E., \& Benford, S. (1995). Endogenous fantasy and learning in digital games. Simulation \& Gaming, 36(4), 483-498.

Henriksen, T. D. (2000). Laring $i$ den simulerede praksis. Universitet Københavns: Købenahavn.

- (2002). Hvordan kan man lare gennem fiction? Teoretiske perspektiver på laring gennem deltagelse $i$ rollespilsformidlet fiktion (how can we learn through fiction? Theoretical perspectives on learning through participation in role-play based fiction). University of Copenhagen.

- (2003). Learning by fiction. In M. Gade, L. Thorup \& M. Sander (eds.), As larp grows up -theory and methods in larp (pp. 108-113). Copenhagen: Knudepunkt.

- (2004). On the transmutation of educational role-play: A critical reframing to the roleplay in order to meet the educational demands. In M. Montola \& J. Stenros (eds.), Beyond role and play. Tools, toys and theory for harnessing the imagination (pp. 107-130). Helsinki, FI: Ropecon ry.

Huizinga, J. (1950). Homo ludens. A study of the play element in culture. London: First Beacon Paperback.

Høyrup, S. (1975). Laboratorie- og sensitivitetstraning. Anvendelsen af intensentiv gruppetraning til social indlaring og -udvikling. København: Gyldendal.

- (2006). Reflection in learning at work. In E. Antonacoloulou, P. Jarvis, V. Andersen, B. Elkjaer \& S. Høyrup (eds.), Learning, working and living. Mapping the terrain of working life learning", Palgrave Macmillian. New York: Palgrave MacMillian.

Koster, R. (2005). Theory of fun for game design. Michigan: PARAGLYPH PRESS.

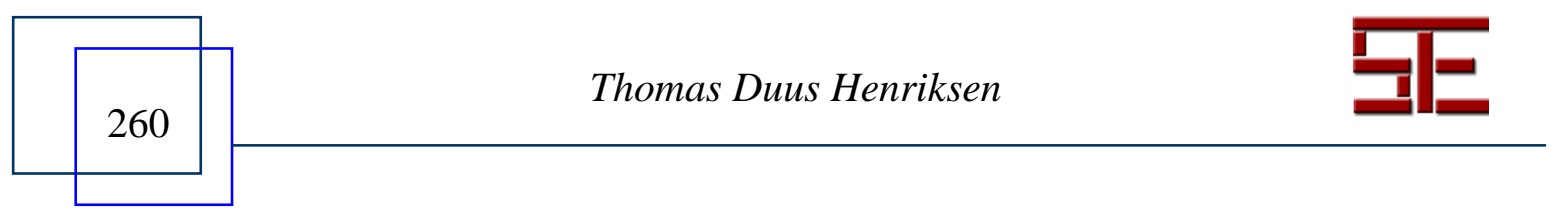




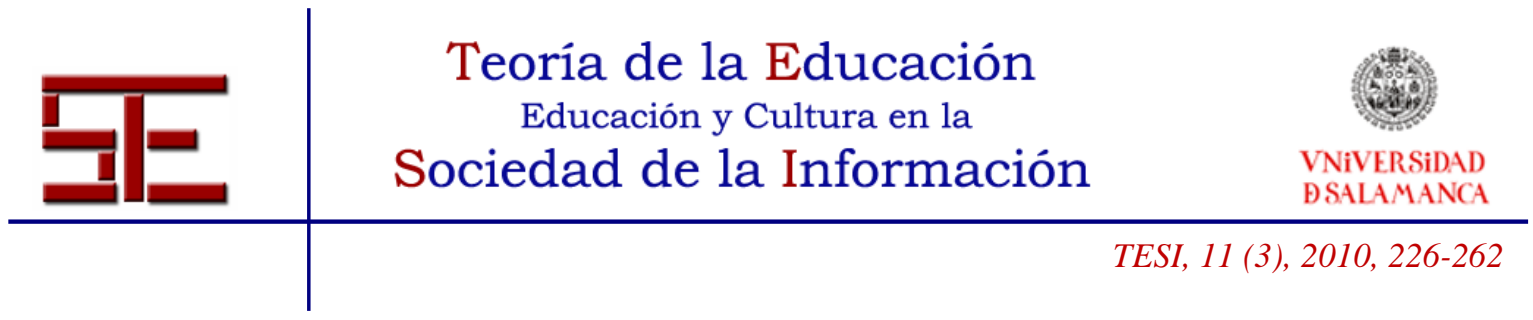

Lave, J. (1999). Læring, mesterlære, social praksis. In K. Nielsen \& S. Kvale (eds.), Mesterlare. Laering som social praksis (pp. 35-53). København: Hans Reitzels Forlag.

Lazerus, R. S., \& Folkman, S. (1984). Stress, appraisal and coping. NY: Springer.

Lepper, M. R., \& Chabay, R. W. (1985). Intrinsic motivation and instruction: Conflicting views on the role of motivational processes in computer-based education. Educational Psychologist, 20(4), 217-230.

Lewin, K. (1947). Group decision and social change. In T. M. Newcomb \& E. L. Hartley (eds.), Readings in social psychology. NY: Holt.

Malone, T. W., \& Lepper, M. R. (1987). Making leaning fun. A taxonomy of intrinsic motivations for learning. In Aptitude, learning and instruction (Vol.3: Conative and Affective Process Analyses). NJ: Lawrence Erlbaum Associates, Inc. Publishers.

Maturana, H. R., \& Varela, F. J. (1992). The tree of knowledge. The biological roots of understanding. Boston: New Science Library.

Merriam, S. B., \& Clark, M. L. (1993). Learning from life experience: What makes it significant? International Journal of Lifelong Education, 12(2), 129-138.

Murray, J. H. (1997). Hamlet on the holodeck. NY: Free Press.

Papert, S. (1996). A word for learning. In Y. Kafai \& M. Resnick (Eds.), Construction in practice. Designing, thinking and learning in a digital world. New Jersey: Lawrence Erlbaum Associates, Publishers.

Papert, S. (1998). Does easy do it? Children, games and learning. Game Developer(June 1998), 87-88.

Paras, B., \& Bizzocchi, J. (2005). Game, motivation, and effective learning: An integrated model for educational game design, DIGRA 2005.

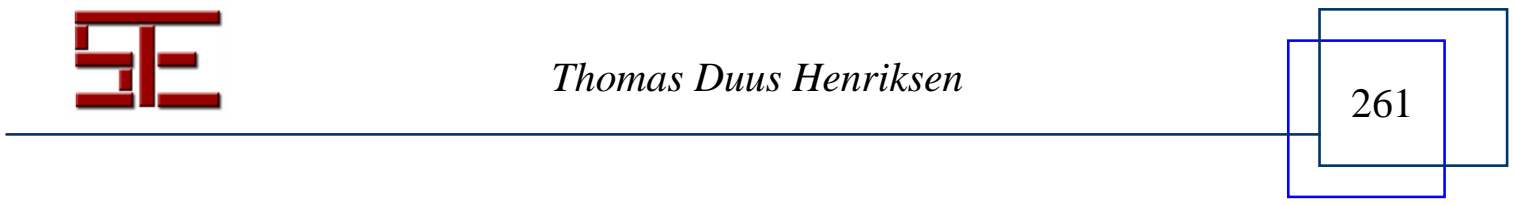




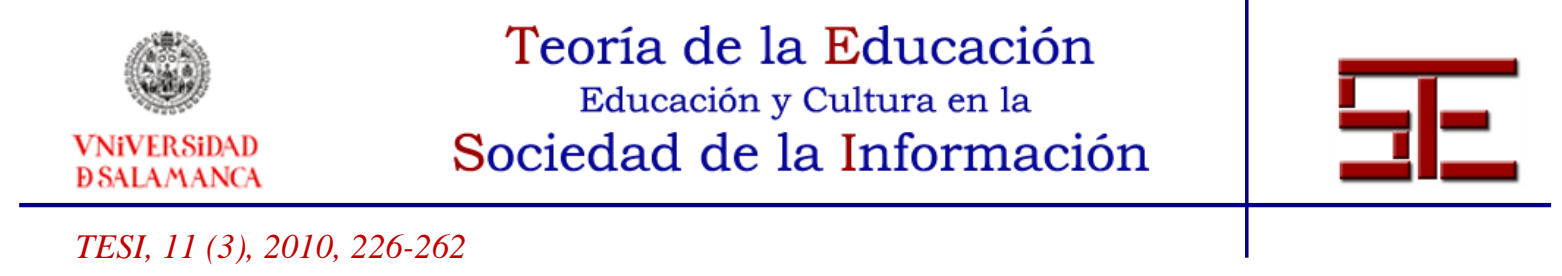

Ryan, M.-L. (1991). Possible worlds, artificial intelligence, and narrative theory: Indiana University Press.

Salen, K., \& Zimmerman, E. (2004). Rules of play - game design fundamentals. Massachusetts: Massachusetts Institute of Technology.

Schein, E. H. (1962). Management development, human relations training, and hte process of influece (Vol. 5: Issues in Training): NTL Washington.

Van Ments, M. (1999). The effective use of role play (2.nd ed.). London: Kogan Page Limited.

Von Glasersfeld, E. (1995). Radical constructivism. A way of knowing and learning. London: The Falmer Press.

Woerkom, M. (2003). Critical reflection at work. Bridging individual and organisational learning. Enschede: University of Twente.

Para citar el presente artículo puede utilizar la siguiente referencia:

Duus Henriksen, T. (2010). Moving educational role-play beyond entertainment, en Orejudo González, J.P. (Coord.) Perspectiva educativa y cultural de "juego de rol". Revista Teoría de la Educación: Educación y Cultura en la Sociedad de la Información. Vol. 11, no 3. Universidad de Salamanca, pp. 226-262 [Fecha de consulta: dd/mm/aaaa]. http://campus.usal.es/ revistas_trabajo/index.php/revistatesi/article/view/7462/7478 